\title{
"Wind Theft" from Onshore Wind Turbine Arrays: Sensitivity to Wind Farm Parameterization and Resolution
}

\author{
SARA C. PRYOR AND TRISTAN J. SHEPHERD \\ Department of Earth and Atmospheric Sciences, Cornell University, Ithaca, New York \\ PATRICK J. H. VOLKER AND ANDREA N. HAHMANN \\ Department of Wind Energy, Danish Technology University, Roskilde, Denmark \\ REBECCA J. BARTHELMIE \\ Sibley School of Mechanical and Aerospace Engineering, Cornell University, Ithaca, New York
}

(Manuscript received 19 September 2019, in final form 3 December 2019)

\begin{abstract}
High-resolution simulations are conducted with the Weather Research and Forecasting Model to evaluate the sensitivity of wake effects and power production from two wind farm parameterizations [the commonly used Fitch scheme and the more recently developed Explicit Wake Parameterization (EWP)] to the resolution at which the model is applied. The simulations are conducted for a 9-month period for a domain encompassing much of the U.S. Midwest. The two horizontal resolutions considered are $4 \mathrm{~km} \times$ $4 \mathrm{~km}$ and $2 \mathrm{~km} \times 2 \mathrm{~km}$ grid cells, and the two vertical discretizations employ either 41 or 57 vertical layers (with the latter having double the number in the lowest $1 \mathrm{~km}$ ). Higher wind speeds are observed close to the wind turbine hub height when a larger number of vertical layers are employed (12 in the lowest $200 \mathrm{~m}$ vs 6), which contributes to higher power production from both wind farm schemes. Differences in gross capacity factors for wind turbine power production from the two wind farm parameterizations and with resolution are most strongly manifest under stable conditions (i.e., at night). The spatial extent of wind farm wakes when defined as the area affected by velocity deficits near to wind turbine hub heights in excess of $2 \%$ of the simulation without wind turbines is considerably larger in simulations with the Fitch scheme. This spatial extent is generally reduced by increasing the horizontal resolution and/or increasing the number of vertical levels. These results have important applications to projections of expected annual energy production from new wind turbine arrays constructed in the wind shadow from existing wind farms.
\end{abstract}

\section{Introduction}

\section{a. Motivation}

"Wind theft" is a colloquial term used to describe the effect wherein wakes from upstream wind turbine (WT) arrays reduce inflow wind speeds to downstream WT arrays. This effect has long been recognized as a potential source of reduced overall system electrical power production efficiency, particularly in offshore environments (Frandsen and Barthelmie 2002) where WT wakes tend to persist farther downstream (Christiansen and Hasager 2005). These WT array-array interactions

Corresponding author: S. C. Pryor, sp2279@cornell.edu have the potential to reduce annual energy production (AEP) from individual wind farms, and at high WT penetration may negatively influence overall systemwide efficiency of electrical power production. By the end of 2018 the WT installed capacity (IC) in the United States was approximately $95 \mathrm{GW}$ and wind turbines supplied approximately $275 \mathrm{TW}$ h to the national electricity grid (AWEA 2019). Estimates of projected expansion of WT IC suggest new additions from wind by the end of 2021 will exceed $90 \mathrm{GW}$ (Froese 2019), and there are scenarios suggesting $20 \%$ of U.S. electricity supply could derive from wind by 2030 (NREL 2008), potentially increasing to $35 \%$ by 2050 (NREL 2015). In 2016 nearly $89 \%$ of U.S. wind farms were located within $40 \mathrm{~km}$ of another wind 
turbine array (Lundquist et al. 2019), and there is anecdotal evidence that at least one-half (and perhaps $84 \%$ ) of all new wind installations in the United States are within the "shadow" of existing wind farms (Dr. P. Moriarty, National Renewable Energy Laboratory, 2019, personal communication). Thus, WT array-array interactions should be considered when locating new developments (i.e., new WT arrays) to properly characterize projected AEP from existing and planned developments.

The right to unimpeded wind capture is a legal concept that is beyond the scope of the current research. It is worth noting that the existence of legal mechanisms to challenge construction of new upstream arrays or to require remuneration for lost revenue or excess loading on existing WT arrays is country, and even county/municipality, specific. For example, "Zopf estimated that the new WT from the other developer could reduce the energy capture of their existing wind farm by up to $15 \%$ or about 230,000 kilowatt hours, amounting to a financial loss of 20,000 euros per year. However, under German law, the wind itself cannot be owned, so Zopf has no legal means to challenge this reduction in energy capture" (van der Horst and Vermeylen 2010).

\section{b. Previous research}

Research presented herein employs limited-area (regional) modeling to examine WT array-array interactions and systemwide efficiency of electricity production from actual land-based WT arrays. This regional focus enables an evaluation of the cumulative impact of actual deployed WTs at relatively high resolution but over an extensive area with multiple WT arrays. It also makes it possible to conduct simulations to assess the sensitivity of the simulation results to both the wind farm parameterization employed and the resolution at which the Weather Research and Forecasting (WRF) Model is applied over a wide range of atmospheric conditions and different climatological seasons. However, it is important to acknowledge that there are scales of motion impacted by WT operation that are not explicitly resolved in models such as WRF that employ "Reynolds averaging" of the Navier-Stokes equations [i.e., Reynolds-averaged Navier-Stokes (RANS) models]. A recent review of mean and second-order flow statistics in the near wake (i.e., at distances downstream from WT of less than five rotor diameters $D$ ) from in situ and remote sensing observations, wind tunnel experiments, large-eddy simulations (LES), and analytical modeling at scales ranging from 1 to $10 \mathrm{~m}$ that cover vortices from WT blades up to those of tens of meters that characterize wakes behind individual WTs can be found in Stevens and Meneveau (2017).

LES models can be applied to generate more detailed depictions of wake structure and evolution than are possible using regional models, but they usually employ periodic lateral boundary conditions and can realistically only simulate relatively small domains because of the computational cost (Berg et al. 2017; Vanderwende et al. 2016). Simulations presented in Churchfield et al. (2012) used a 1-2 m mesh around the turbines reducing to $10 \mathrm{~m}$ in the far field, had a vertical extent of $1 \mathrm{~km}$ (where the upper boundary is specified as a zero-stress impenetrable lid) and a horizontal extent of $3 \mathrm{~km} \times 3 \mathrm{~km}$. A recent review suggested computational costs associated with LES of wind farm flows are typically " $\sim 10^{3}-10^{4}$ CPU hours per simulation", (Porté-Agel et al. 2020). LES typically use either actuator-disk models (i.e., in a manner somewhat analogous to that used in wind farm parameterizations designed for use with RANS models such as WRF) (Sanderse et al. 2011), or (more commonly) more computationally expensive actuator-line models (Troldborg et al. 2010) to represent the WT rotor aerodynamics (Troldborg 2008). Hybrid models that resolve some aspects of wake rotation behind the rotor are also employed in LES (Dörenkämper et al. 2015). At the other end of the scale in terms of spatial domain, models that cover the entire globe necessarily operate at much coarser grid resolution $(\sim 30-100 \mathrm{~km})$ and without specific information regarding WT locations and power and thrust curves, but they can be employed to examine the potential impacts from largescale global deployment of WTs (Fitch 2015). Our work does not seek to characterize individual WT wakes or to cover the entire globe. Instead, research reported herein employs tools appropriate to characterizing the cumulative downstream impact on the far-field flow from WT arrays (beyond $\sim 5 D$ ) and systemwide electricity generation efficiency.

\section{c. Wind farm parameterizations in WRF}

Two wind farm parameterizations are available for use in the WRF Model to characterize wind farm wakes: 1) the Fitch parameterization (Fitch et al. 2012), and 2) the Explicit Wake Parameterization (EWP) scheme (Volker et al. 2015). The Fitch parameterization has been part of WRF Model releases since version 3.3. Thus, although early research used simplified approximations (e.g., enhanced roughness blocks; Keith et al. 2004) to represent wind turbine arrays, as indicated by the brief precis of selected prior research provide in 
Table 1, most research with regional models conducted during the last decade has employed the Fitch parameterization. The studies described in Table 1 have been selected to represent a sample of past research that shows the breadth of research questions that have been addressed for onshore WT arrays: WT array wake effects, array-array interactions and power production, climate impacts from WT arrays, and theoretical limits on kinetic energy extraction by WTs. As shown, the simulations have been conducted over a wide range horizontal grid spacings (from $<1$ to $50 \mathrm{~km}$ ) and study domains, have varied in vertical discretization from relatively coarse with only 3 to more than 12 levels in the lowest $100 \mathrm{~m}$ of the atmosphere, and have used idealized case studies, domains with uniform WT types and dimensions [hub height $(\mathrm{HH}), D$, and rated capacity (RC)], or real WT deployments with a range of WT types and prescribed or real-world meteorological inputs. Key findings of the prior research summarized in Table 1 that motivate the current research are as follow: 1) discrepancies in the estimates of the downstream recovery distance for full wind farm wakes due, in part, varying inflow conditions, wind farm layouts, model resolutions and wind farm parameterizations; 2) dependence of the inflow fidelity to model resolution; 3 ) evidence that the Fitch wind farm parameterization may overestimate the intensity and persistence of wind farm wakes.

In both wind farm parameterizations, Fitch and EWP, the WT drag force induced on grid cells across the rotor plane is determined from the WT thrust coefficient and the incident wind speed profile. An estimate of the power produced by the WT(s) in each grid cell and model time step is derived using the WT-specific power curve and the gridcell-averaged incident wind speed profile. There are number of differences between Fitch and EWP. One pertains to differences in the manner in which the extraction of kinetic energy over the rotor plane is described and allocated in the vertical coordinate system. This leads to a gridcell-averaged lofting of the wake from the WT hub height in the Fitch parameterization, while the maximum deficit is centered at the WT hub height in EWP (Volker et al. 2015). There are also differences in the manner in which WT are allocated to horizontal grid cells. As originally written, the code for EWP uses "floor" to allocate WTs to the appropriate WRF grid. Thus, if the conversion from latitude and longitude yields a WT to a position in the WRF grids of $116.8,121.6$ the WT would be allocated to the grid 116, 121. In the Fortran code for the Fitch parameterization, the Fortran command "nint" is used, which means the WT would be allocated to the grid cell 117, 122. For consistency across the two approaches, in this analysis EWP has been modified to mimic the approach adopted in Fitch to allocated WTs to individual WRF grid cells. The most consequential difference between the parameterizations is the treatment of the turbulence addition from WTs within a grid cell and the impact on wake dynamics (Volker et al. 2015). In brief, in the Fitch parameterization the fraction of kinetic energy extracted by the WT that is not converted into electrical power is estimated from the difference in the WT thrust coefficient and the power coefficient. This residual term is assumed to represent turbulent kinetic energy (TKE) and is added to the atmosphere via the TKE equation in the RANS formulation (Fitch et al. 2012). The additional TKE scales with the wind speed cubed. It typically greatly exceeds that from shear production in the vicinity of the WTs and is critical to enhancing wake dissipation in grids cells containing WT and in nearby downstream grid cells. In EWP added TKE due to the action of the WTs derives solely from the shear induced in the vertical wind speed profile due to the velocity deficit. The increase in gridcell-average turbulence resulting from WTs is treated using a subgrid turbulence diffusion equation to induce within-gridcell vertical expansion of the wake (Volker et al. 2015). In this approach the wake-expansion length scale is a function of the turbulent diffusion coefficient (from the WRF-PBL scheme), the wind speed at hub height, and an initial length scale $\sigma_{0}$ that is scaled with the rotor diameter of a "typical WT" ( $\sigma_{0}=1.7 R_{0}$, where $R_{0}$ is the rotor radius). Given these differences in the wind farm parameterizations, it is reasonable to expect that they may yield different wake profiles and potentially different wake recovery and impacts from WT arrays on systemwide power production efficiency and other atmospheric conditions (e.g., near-surface climate effects). Further, it can be postulated that both will exhibit sensitivity to the resolution at which the WRF Model is applied, particularly given the influence of horizontal resolution on the wind climate (Zhao et al. 2016). With respect to this latter point, previous research has indicated wind speeds close to WT HH are slightly higher in both enhanced horizontal and vertical resolution simulations (Larsén et al. 2012). However, the impact is dependent on the moment of the distribution being considered and the specific simulation domain. For example, the mean annual wind speed at $100 \mathrm{~m}$ differed by $<1.5 \%$ in simulations using 6 or 14 layers in the lowest $200 \mathrm{~m}$ and a horizontal grid spacing of $5 \mathrm{~km}$ over the Baltic Sea and surrounding land areas, but the higher number of vertical levels resulted in slightly lower annual mean wind speeds (Hahmann et al. 2015). A further simulation over complex terrain showed modest changes in wind speed at $60 \mathrm{~m}$, resulting from an increase in 


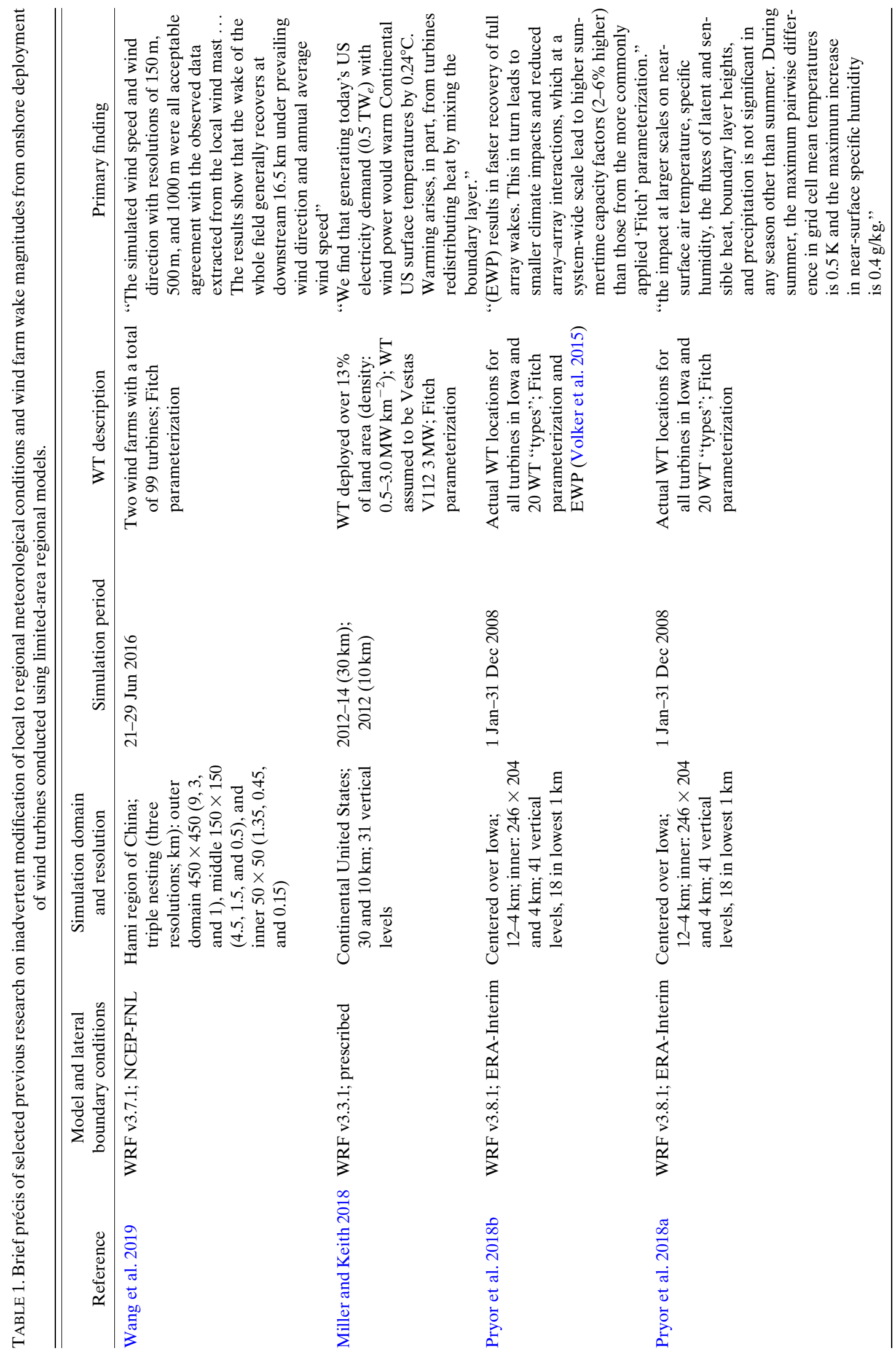




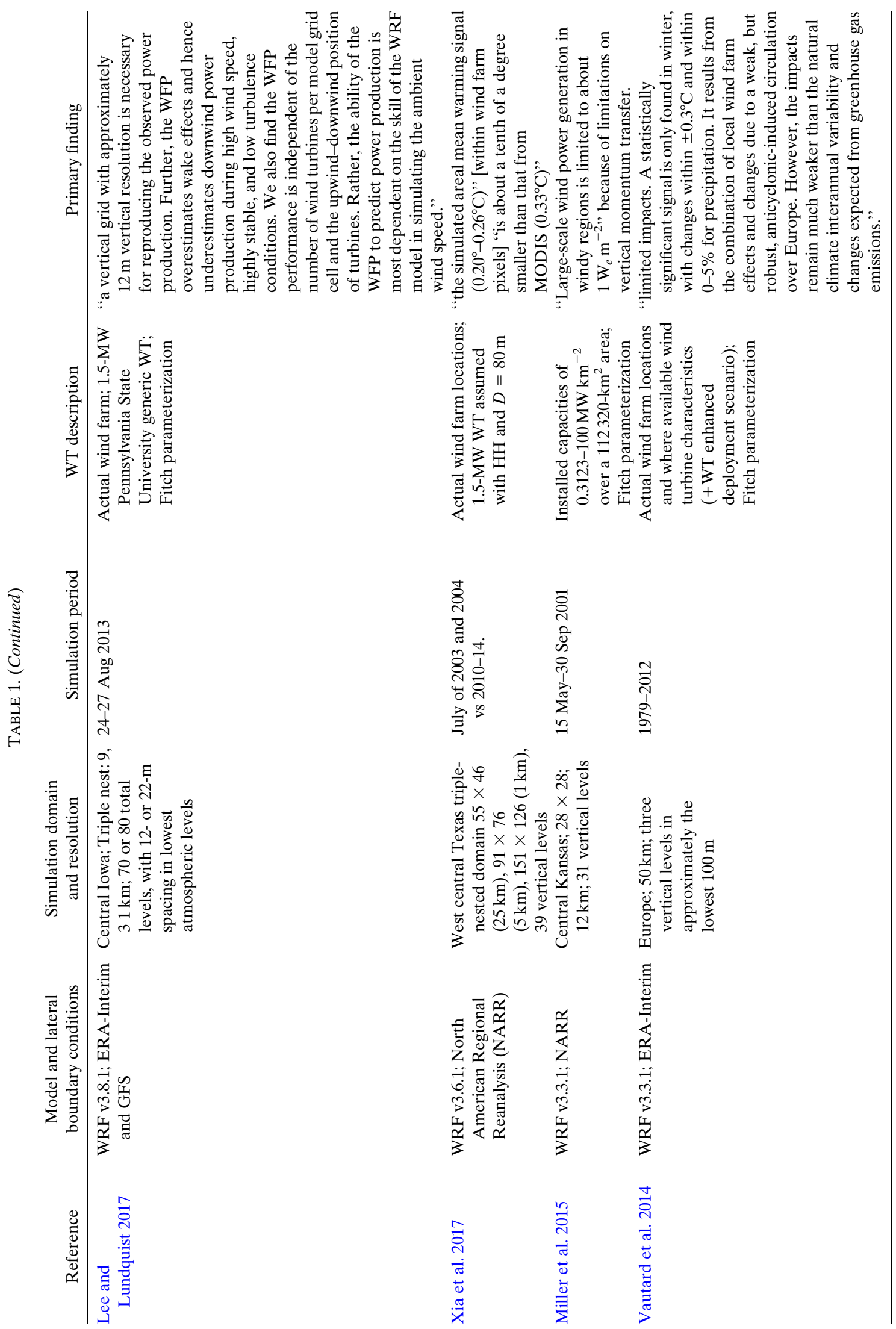




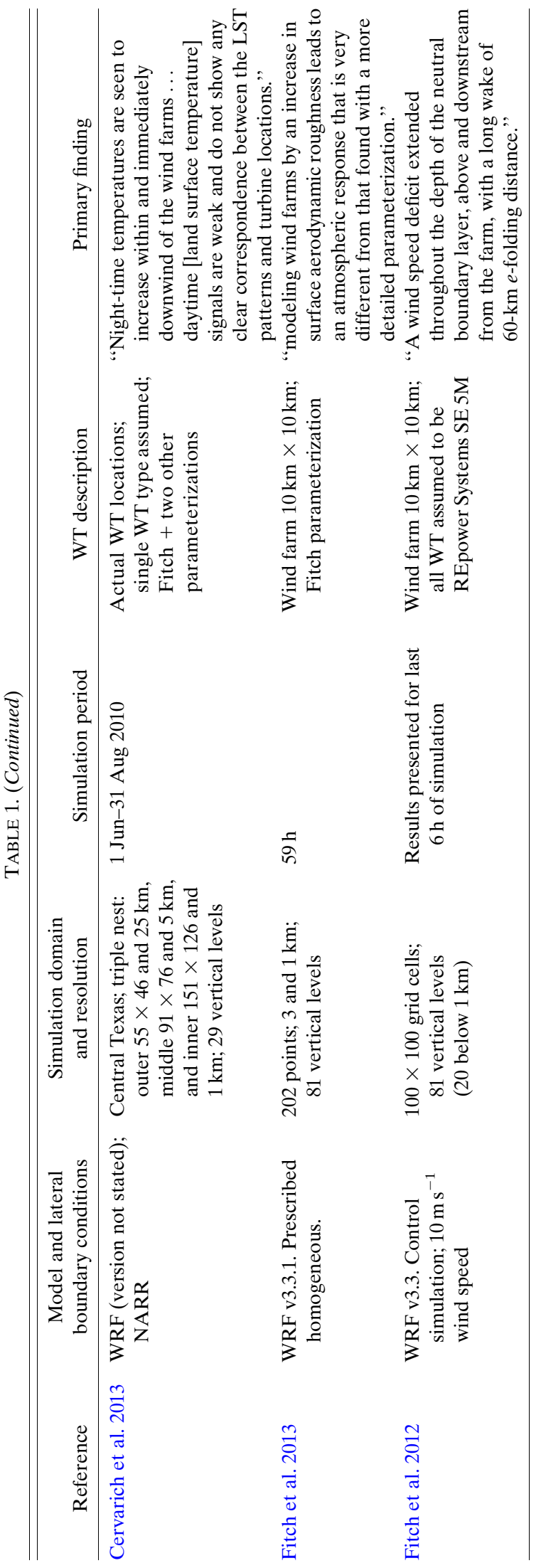

horizontal grid spacing from 3 to $1.2 \mathrm{~km}$, and a small reduction in the bias relative to observations (Carvalho et al. 2012). Using idealized simulations with flat terrain, and a geostrophic forcing of $10 \mathrm{~m} \mathrm{~s}^{-1}$ (Fitch et al. 2012) found only a modest impact from doubling the vertical resolution on wind speeds at WT-relevant heights. The lower-resolution simulation (with seven model layers below $200 \mathrm{~m}$ ) showed higher wind speeds (of up to $0.2 \mathrm{~m} \mathrm{~s}^{-1}$ ) below $50 \mathrm{~m}$ AGL but a difference of $<0.1 \mathrm{~m} \mathrm{~s}^{-1}$ above that. When the wind farm parameterization was active, the lower-resolution simulation was associated with slightly larger velocity deficits (by up to $0.1 \mathrm{~m} \mathrm{~s}^{-1}$ ). When the horizontal grid spacing was halved from 1 to $2 \mathrm{~km}$, they found that in the absence of the wind farm the change in wind speed was negligible; the wind speed reduction was slightly amplified (by up to $0.1 \mathrm{~m} \mathrm{~s}^{-1}$ ) in the 1-km-resolution simulation with Fitch. The sensitivity analysis conducted by Fitch et al. (2012) to assess the impact of resolution on WT downstream effects used a control resolution of 81 vertical levels, 30 of which were below $1 \mathrm{~km}$ and 8 of which intersected the rotor area, and a lower vertical resolution using half as many vertical levels, 15 of which were below $1 \mathrm{~km}$ and 4 of which intersected the rotor area. These vertical resolutions bracket the vertical resolution in terms of the number of vertical layers in the lowest $1 \mathrm{~km}$ and the number across the rotor plane in the simulations presented here. Fitch et al. (2012) concluded, "the sensitivity to vertical resolution appears to be less than $10 \%$ of the response to the wind farm within the rotor area and downstream." More recent simulations of offshore wind farms that also used idealized meteorological conditions indicated important differences in modeled wake profiles within WT arrays and at short distances downstream of grid cells containing WT due to differences in model vertical resolution even for identical inflow conditions (Volker et al. 2015). Simulations over and downwind of a large onshore wind farm (in Iowa) also illustrated sensitivity of wake intensity to vertical discretization and found improved agreement with 10min average power production data for a simulation with a vertical grid space of $12 \mathrm{~m}$ in the lowest $400 \mathrm{~m}$ of the atmosphere over one where the vertical levels were spaced at $22 \mathrm{~m}$ intervals (Lee and Lundquist 2017). However, the degree of improvement with enhanced vertical resolution (and indeed the presence or absence of improvement as measured by average bias) was not uniform across the four days of simulation (Lee and Lundquist 2017). Authors of an additional study that focused on one day of simulations for a large offshore WT array stated that, "significant improvement was achieved by Lee and Lundquist (2017) by using three and six vertical levels below and within the rotor 
area, instead of one level and four levels, respectively. Nevertheless, in this study we obtained results closest to the observation with one full level below the rotor area and only three levels within the rotor area. This vertical resolution is equal to a vertical spacing of $35 \mathrm{~m}$ in the lowest $200 \mathrm{~m}$ and increasing to $100 \mathrm{~m}$ at $1000 \mathrm{~m}$ above MSL" (Siedersleben et al. 2018). Thus, there appears to be considerable spatiotemporal variability in the actual optimal model configuration for wind farm wake analyses. This is likely due, at least in part, to variations in atmospheric properties and wind farm configurations. Long duration simulations such as those presented here that are conducted using large numbers of grid cells naturally need to balance computational cost against possible performance enhancement achieved from increasing the number of horizontal grid cells or vertical resolution.

Previous research has demonstrated a positive bias in wake intensity in the Fitch parameterization and therefore a negative bias downwind power production "during high wind speed, highly stable, and low turbulence conditions" for simulations over a large wind farm in Iowa (Lee and Lundquist 2017). Others have indicated that TKE addition in the Fitch parameterization may lead to excess turbulence levels and mixing (Vanderwende et al. 2016).

Consistent with the summary above that compares the two wind farm parameterizations, prior research has also revealed important differences in wake profiles, downstream recovery and also gross capacity factors (CF) from the Fitch and EWP schemes (Pryor et al. 2019; Volker et al. 2015). For example, a numerical experiment describing the wind speed field inside and downwind of very large wind farms $\left(10^{5} \mathrm{~km}^{2}\right)$ with a WT spacing of $10.5 \mathrm{D}$ in three regions with distinct wind speed and roughness conditions showed wind speeds recovered to $2 \%$ above the maximum velocity deficit faster in EWP than Fitch (Volker et al. 2017). Further simulations conducted at $1 \mathrm{~km}$ horizontal grid spacing for the offshore WT array at Horns Rev in Denmark $(80 \mathrm{WT}$; IC $=160 \mathrm{MW})$ using an inflow of $10 \mathrm{~m} \mathrm{~s}^{-1}$ found the downstream recovery distance to $<5 \%$ velocity deficit was $21 \mathrm{~km}$ in EWP and $11 \mathrm{~km}$ in Fitch (Volker et al. 2015). The primary difference in the wake recovery between the two schemes for the offshore case study was observed in the first two grid cells behind the wind farm where higher TKE advected from the wind farm in the Fitch scheme caused a more rapid recovery of the wake deficits. The maximum TKE difference (wind farm simulation minus control) at any vertical level and downstream distance was $1.9 \mathrm{~m}^{2} \mathrm{~s}^{-2}$ in Fitch and $0.3 \mathrm{~m}^{2} \mathrm{~s}^{-2}$ in EWP. The TKE enhancement was simulated to occur at greater downwind distances and heights in EWP than Fitch. In contrast to these offshore studies, simulations for an onshore wind farm cluster in Iowa (comprising a total of $223 \mathrm{WT}$ and an IC of $365 \mathrm{MW}$ ) conducted at a horizontal resolution of $4 \mathrm{~km}$ showed the downstream distance for the wake to recover to a normalized velocity deficit close to WT HH of $<5 \%$ was found to be longer in simulations with Fitch than with EWP (12 and $8 \mathrm{~km}$, respectively) (Shepherd et al. 2020). There are three primary possible sources of the discrepancies between the results for the Horns Rev I offshore wind farm [presented in Volker et al. (2015)] and the simulations of the onshore large wind farm cluster [presented in Shepherd et al. (2020)]:

1) The length scale used in EWP for the within-gridcell wake expansion $\left(\sigma_{0}\right)$ was tuned using the Horns Rev WTs and may not be appropriate to the WTs used in the onshore case. However, the WTs deployed at Horns Rev have similar physical dimensions to those used in the analysis of Shepherd et al. (2020): $\mathrm{HH}=70$ (Horns Rev I) and 80-100 (Iowa) $\mathrm{m} ; D=80$ and 77-101 m, respectively; $\mathrm{RC}=2.0$ and $1.5-2.3 \mathrm{MW}$. Further, the sensitivity analysis of Volker et al. (2015) indicated only a weak dependence of downstream wake recovery on $\sigma_{0}$.

2) There are differences in the stability and freestream TKE conditions on- and offshore. It can be hypothesized that the lower ambient TKE offshore means the TKE addition from WT to the ambient TKE budget in the Fitch scheme versus the within-gridcell wake-expansion approach in EWP causes differential atmospheric responses according to the prevailing atmospheric conditions.

3) There are differences in the resolution response of the EWP and Fitch parameterization schemes since the two studies highlighted here used 4- and 1.12-km horizontal grid spacings, respectively.

Research presented herein focuses on the third of these hypotheses but partly addresses the second hypothesis by including simulations over a wide range of atmospheric conditions (and thermal stratifications).

\section{Methods}

\section{a. Simulations}

Here we examine whether the wind farm parameterization schemes available for use in WRF and the differences between them exhibit sensitivity to the model vertical and horizontal grid spacing using actual wind turbine deployments and specifications and long-term (9 month) simulations conducted within lateral boundary conditions (LBC) from a reanalysis (ERA-Interim; Dee et al. 2011) to represent a realistic wind climate. The ERA-Interim reanalysis has been widely used as 
LBC for regional simulations under major climate science initiatives such as the Coordinated Regional Downscaling Experiment (CORDEX; Giorgi and Gutowski 2015) and was also used in the New European Wind Atlas project (Sile et al. 2018).

The output from simulations for the climate from December 2007 to August 2008 (November 2007 was used as spinup) is presented herein for a domain that is centered over the midwestern United States; the simulations were conducted using the settings given in Table 2 . The outer domain (d01) comprises $149 \times 149$ grid cells and is resolved using a grid spacing of $12 \mathrm{~km} \times$ $12 \mathrm{~km}$. It covers an area extending from $\sim 103^{\circ}$ to $83^{\circ} \mathrm{W}$ and from $\sim 33.5^{\circ}$ to $49.5^{\circ} \mathrm{N}$. In the inner domain, WRF is applied at convection-permitting resolutions of 4 and $2 \mathrm{~km}$ with either 41 vertical layers or with double the number in the lower levels of the atmosphere (57 layers). According to the USGS database (https:// eerscmap.usgs.gov/uswtdb/), over 3100 WTs (IC of approximately $5.7 \mathrm{GW}$ ) were operating in Iowa as of the end of 2014. These WTs are allocated to the appropriate WRF grid cell (Fig. 1) and are characterized using WT specific $\mathrm{HH}, D$, power, and thrust curves as in our previous research (Pryor et al. 2018a) for use with the two wind farm parameterizations. In all simulations, advection of TKE is enabled as in research conducted by Fitch (Fitch 2015; Fitch et al. 2012, 2013) to allow for effective downstream propagation of the TKE produced by the wind turbine arrays. Recent work has indicated use of TKE advection improves the degree of agreement with observations downstream of an offshore wind farm (Siedersleben et al. 2020).

The horizontal and vertical resolutions employed herein are informed by physical constraints, prior research, and computational limitations. With respect to horizontal grid spacing, it is important to note that the wind farm parameterizations used in regional models do not include interactions between WTs within a grid cell (i.e., all WTs in a grid cells are subject to the same inflow wind speed profile). The optimal horizontal grid spacing is thus a balance between the desire to minimize this "missing" wake component (i.e., minimize the number of WT in a grid cell) while being cognizant that the wind farm parameterizations treat only the far wake and thus should not employ horizontal resolutions higher than 5D (Fitch 2016). The majority of the WT deployed in the United States have $D \sim 100 \mathrm{~m}$, which suggests a minimum resolution of $500 \mathrm{~m}$. As also noted in Fitch (2016), a further limitation on minimum horizontal resolution derives from considerations of the validity of assumptions that underpin the PBL schemes employed in RANS models. Under convective conditions, this effectively means that horizontal grid spacings should not
TABLE 2. System configuration, physics settings, and version number used in the WRF simulations.

\begin{tabular}{ll}
\hline \hline $\begin{array}{l}\text { WRF version number } \\
\text { Compiler }\end{array}$ & V3.8.1 \\
Operating system & GNU Fortran v5.4 \\
& Ubuntu v18.04 with WRF in a Docker \\
& container \\
Physics settings used & Scheme chosen \\
in WRF & \\
Microphysics & Eta (Ferrier) (Ferrier et al. 2002) \\
Longwave radiation & Rapid Radiative Transfer Model \\
& (RRTM) (Mlawer et al. 1997) \\
Shortwave radiation & Dudhia (Dudhia 1989) \\
Surface layer physics & MM5 similarity scheme \\
& (Beljaars 1995) \\
Land surface physics & Noah land surface model (Tewari \\
& et al. 2004) \\
Planetary boundary layer & Mellor-Yamada-Nakanishi-Niino \\
& 2.5 (Nakanishi and Niino 2006) \\
Cumulus parameterization & Kain-Fritsch (Kain 2004) (None in \\
& d02_XXXX) \\
\hline
\end{tabular}

be below about $1 \mathrm{~km}$. For these reasons the two horizontal grid spacings considered herein for the inner domain (d02) are 2 and $4 \mathrm{~km}$. The inner domain (d02) is thus resolved at 4 or $2 \mathrm{~km}$ and comprises $246 \times 204$ (or $492 \times 408)$ grid cells (Figs. 1a,b).

Irrespective of the wind farm parameterization, it is expected that increasing the vertical grid resolution of the model will yield improved representation of the vertical structure of the atmosphere including features such as wind shear and low-level jets (Draxl et al. 2014; Nunalee and Basu 2014; Rife et al. 2010). Thus, two configurations are considered here: one that employs 41 vertical levels (the default in the name list example provided in WRF releases), and a second that uses 57 vertical layers, where the 20 additional levels are employed at one-half of the sigma increment in the lowest 20 levels in the 41-level simulation.

Throughout this paper, examples of wake behavior are presented for a subregion of $\mathrm{d} 02$ that covers an area from $42^{\circ}$ to $43^{\circ} \mathrm{N}$ and from $95.2^{\circ}$ to $92.4^{\circ} \mathrm{W}$ and thus is centered on a cluster of wind turbine arrays located in west-central Iowa and referred to herein as the Pomeroy cluster. This cluster of wind farms has a total of 223 WT and an IC of $365 \mathrm{GW}$ (location is shown in Fig. 1b). It actually comprises five developments that were installed between 2007 and 2012 and includes 40 Gamesa G90 2.0-MW WTs, 13 Siemens SWT-2.3-101 WTs, and 170 General Electric GE-1.577 WTs. The hub heights and rotor diameters range from 80 to $100 \mathrm{~m}$ and from 77 to $101 \mathrm{~m}$, respectively. The density of installed capacity in the western portion of the cluster of WT arrays is $\sim 4 \mathrm{MW} \mathrm{km}^{-2}$, and in the eastern portion it is $\sim 2 \mathrm{MW} \mathrm{km}^{-2}$. As shown in Fig. 2 , when the model is deployed at either $4-$ or $2-\mathrm{km}$ 
(a) d01

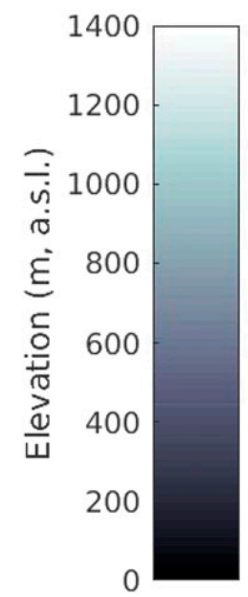

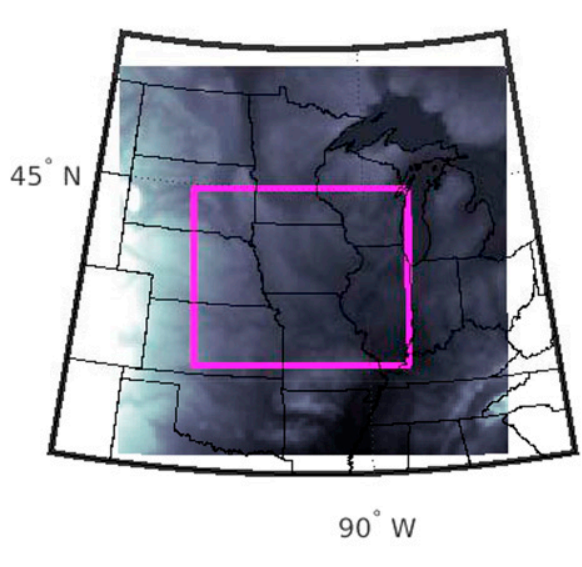

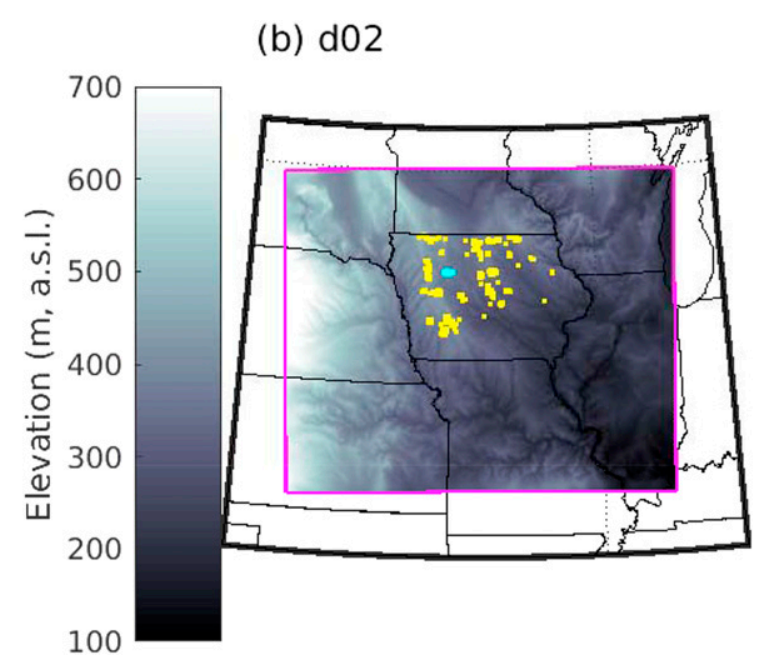

(b) $\mathrm{d} 02$

FIG. 1. (a) Elevation of each $12 \mathrm{~km} \times 12 \mathrm{~km}$ grid cell in the outer domain, with d02 shown by the magenta outline. (b) Elevation in the inner domain ( $\mathrm{d} 02$ ) when resolved at $4 \mathrm{~km} \times 4 \mathrm{~km}$. Grid cells containing WT (when run at $4 \mathrm{~km} \times 4 \mathrm{~km}$ ) are shown in yellow. The wind farm cluster referred to herein as Pomeroy is shown by the cyan grid cells.

horizontal grid spacings the entire cluster functions as a single entity (i.e., there are no grid cells with zero IC). Two other large wind turbine arrays are also included in this subarea of d02: the Carroll and Victory projects. They have total installed capacities of 150 and $83.2 \mathrm{MW}$, respectively and are located southwest of Pomeroy. The Carroll project comprises 100 GE-1.5-77 WTs $(\mathrm{HH}=$ $80 \mathrm{~m}$ ) and has an approximate installed capacity density of $\sim 2 \mathrm{MW} \mathrm{km}^{-2}$. The layout of the Victory project is highly irregular and has lower installed capacity densities; it comprises $52 \mathrm{GE}-1.6-87(\mathrm{HH}=80 \mathrm{~m})$ WTs. The mean height of each sigma layer in WRF is computed from the gridcell terrain elevation and time- (and space-) varying base state geopotential and perturbation geopotential values from each level. In the simulations with 41 vertical layers, over the Pomeroy subregion there are 3 layers below $100 \mathrm{~m}, 6$ below $200 \mathrm{~m}$, and 8 below $300 \mathrm{~m}$. For the enhanced vertical resolution (57 layers) there are 6 layers below $100 \mathrm{~m}, 12$ below $200 \mathrm{~m}$, and 17 below $300 \mathrm{~m}$ (Fig. 3).

In summary, three sets of WRF simulations are performed: one conducted at 4-km horizontal grid spacing with 41 layers and two others with halved horizontal grid spacing $(2 \mathrm{~km} \times 2 \mathrm{~km}$ grid cells $)$ and doubled vertical resolution in the lowest portion of the atmosphere (i.e., a total of 57 layers in the vertical direction). In all cases, the simulations are configured such that a single outer domain is used and three inner domains are simultaneously computed within it. In the first inner domain (d02_noWT) no WT parameterization is employed, in the second the real WT locations and specifications are used with the Fitch parameterization (d02_Fitch), and in the third the real WT locations and specifications are used with the EWP parameterization (d02_EWP). The decision to run three "simultaneous" inner domains was made in an attempt to avoid differences in independent simulations such as those presented in Pryor et al. (2018b) that may arise from numerical sources (see discussion below). The number ordering of the inner domains was identical for all simulations presented herein and was d02_noWT, d02_Fitch, and then d02 EWP. To run multiple overlapping inner domains for noWT, Fitch, and EWP a number of changes must be made to the WRF registry [see the documentation in Volker et al. (2015)].

\section{b. Statistical methods}

Wind components, power, and TKE are output every 10-min from the three sets of simulations conducted at the different horizontal and vertical resolutions. These parameters are analyzed at the model sigma levels (i.e., without vertical extrapolation) to examine the following:

1) We wish to determine whether the magnitude of systemwide gross CF differ between the two parameterizations, are a function of resolution, and exhibit seasonal variability in terms of response to resolution. This analysis thus focuses on understanding the macroscale impact on projected electricity generation efficiency from all WTs in Iowa. Accordingly, gross power production from the two wind farm parameterizations and all WTs deployed in Iowa as of the end of 2014 in each 10-min period is used to derive estimates of electricity generation in each simulated calendar month in gigawatt hours and to compute gross CF by summing all power production values in each $10-$ min period and then dividing by the 
(a)

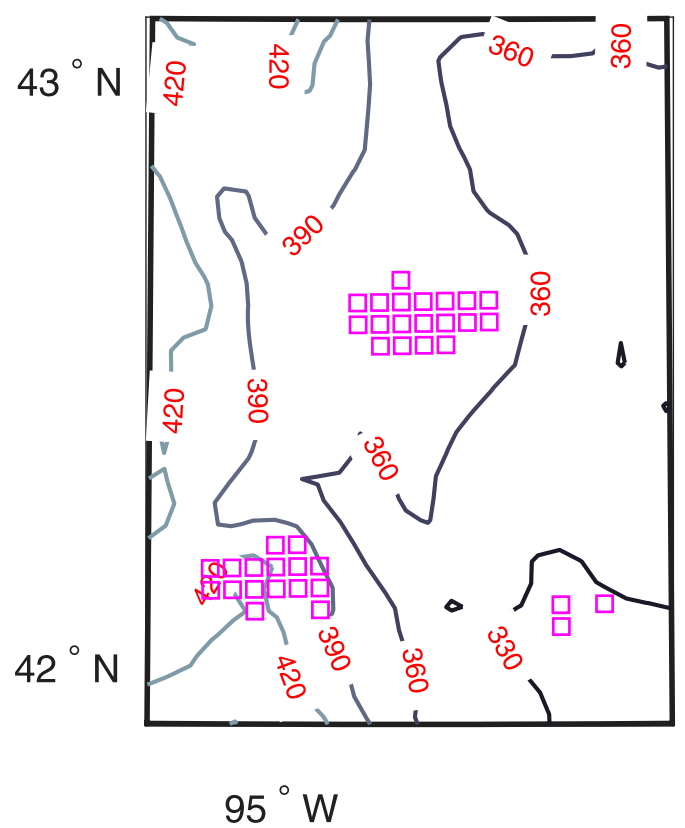

(b)

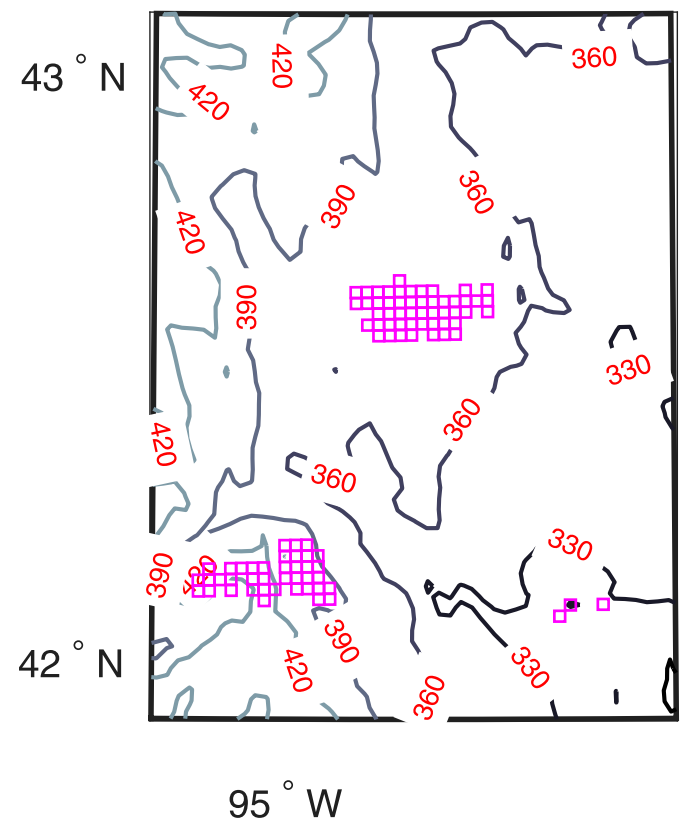

FIG. 2. The mean terrain height (m MSL) of each grid cell in the portion of the domain covering the Pomeroy wind cluster when simulated at (a) 4 and (b) $2 \mathrm{~km}$. Also shown (by the magenta-outlined squares) are grid cells that contain one or more $\mathrm{WT}$ at the two horizontal grid spacings.

total IC. These simulated gross CF exclude factors such as curtailment for grid management, downtime for operations and maintenance, and also near-wake effects since all WTs within a WRF grid cell experience the same inflow profile. Therefore, gross CF exceed observed (net) $\mathrm{CF}$, which implicitly includes reductions to power production due to these effects.

2) We wish to determine whether downstream wake recovery distances at hub height from a wind farm cluster exhibit substantial and consistent responses to model resolution for both wind farm parameterizations. Omnidirectional wake deficits are computed and presented to characterize the relative rates of wake recovery. Using wind speed output $\left(\mathrm{WS}_{\mathrm{d} 02 \_\mathrm{Xxxx}}\right.$, where $\mathrm{XXXX}$ is Fitch or EWP, and $\left.\mathrm{WS}_{\mathrm{d} 02 \_ \text {nowT }}\right)$ for each grid cell $(x, y)$ and vertical level $(z)$ in every 10 -min period $(t)$ the median fractional velocity deficit $v d_{(x, y, z)}$ is computed as

$$
\begin{aligned}
& v d_{(x, y, z)} \\
& \quad=\operatorname{median}\left[\frac{\mathrm{WS}_{\mathrm{d} 02 \_\mathrm{XXXX}(x, y, z, t)}-\mathrm{WS}_{\mathrm{d} 02 \_\operatorname{noWT}(x, y, z, t)}}{\mathrm{WS}_{\mathrm{d} 02 \_n \mathrm{nTT}(x, y, z, t)}}\right] .
\end{aligned}
$$

Note that we use the median and not the mean because the velocity deficits are not normally distributed, rendering the mean an unstable estimator of the central tendency. To provide a quantitative description of wake recovery from the two schemes at the three resolutions, we quantify the number of grid cells in the Pomeroy subdomain that have median fractional velocity deficits in excess of $10 \%, 5 \%$, and $2 \%$.

3) We wish to determine whether the vertical profiles of wakes downstream from wind array clusters exhibit substantial and consistent responses to model resolution in the two wind farm parameterizations. Three-dimensional cross sections of $v d_{(x, y, z)}$ for the two parameterizations and the three resolutions are derived for the Pomeroy region, along with assessments of the median added TKE [i.e., TKE from the wind farm simulations (d02_Fitch and/or d02_EWP) minus d02_noWT].

It is important to recall that, as discussed above, the influence of model resolution on wake behavior and simulated electrical power production is not only a factor of the dependence of the wind farm parameterizations on resolution but also the influence on the wind regime. Thus, we also examine the differences in the wind climate close to WT HH in the d02_noWT output at the three different resolutions. In this analysis, the 10-min output from d02_noWT is used to compute wind speeds in each grid cell from the layer closest to the WT HH of the Pomeroy cluster (model layer 3 in the 


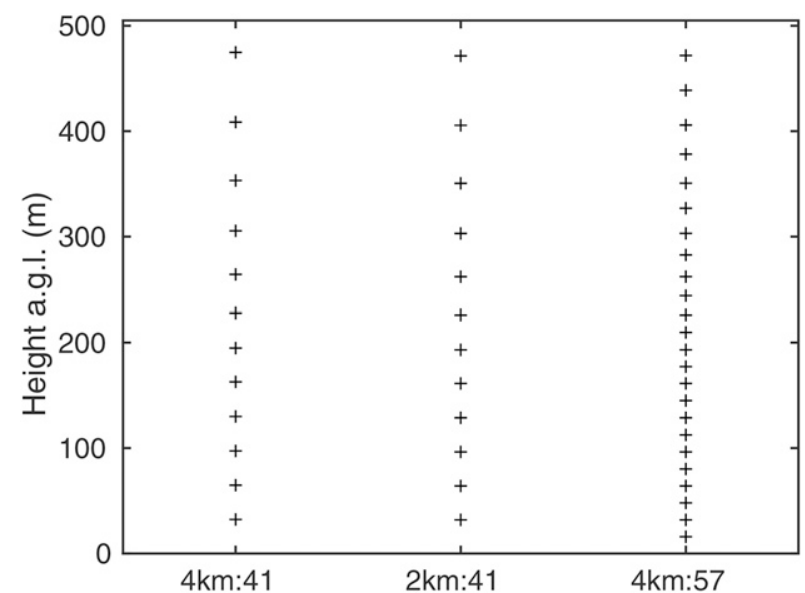

FIG. 3. The mean height AGL of the sigma coordinate levels in the portion of the domain covering the Pomeroy area (see Figs. 1 and 2 for the location of this cluster). The three simulation resolutions are $4-\mathrm{km}$ horizontal grid spacing with 41 vertical layers (4 km:41), 2-km horizontal grid spacing with 41 vertical layers ( $2 \mathrm{~km}: 41)$, and 4-km horizontal grid spacing with 57 vertical levels (i.e., 2 times the density of vertical leaves in approximately the lowest $2 \mathrm{~km})(4 \mathrm{~km}: 57)$. The mean heights are computed using the gridcell mean terrain elevation and time- (and space-) varying base state geopotential height and the perturbation geopotential height.

41-layer simulation and model layer 6 in the 57-layer simulation). The mean and 90th-percentile wind speeds are derived from each of the raw time series from d02_noWT for the three different resolutions. For visualization, the resulting monthly wind speed time series $U$ from all grid cells in the subdomain centered over the Pomeroy cluster are also fitted to Weibull distributions using maximum likelihood methods to derive the distribution parameters ( $A$ and $k$, and confidence intervals thereon) (Pryor et al. 2004; Wilks 2011):

$$
f(U)=\frac{k}{A}\left(\frac{U}{k}\right)^{k-1} \exp \left[-\left(\frac{U}{k}\right)^{k}\right] .
$$

\section{Results}

\section{a. Wind speed distributions at wind turbine hub heights as a function of resolution}

The Weibull distributions of wind speeds close to WT $\mathrm{HH}$ (mean $\sim 94 \mathrm{~m}$ AGL) for the region around the Pomeroy wind farm cluster in d02_noWT output are qualitatively similar in all months in output from the three model resolutions. But there is an enhancement of wind speeds in the simulations with higher vertical resolution. In all calendar months the probability distributions of wind speeds close to WT HH are shifted right and exhibit heavier right tails in the 4-km 57-vertical-layer simulations than in the other two simulations, which are considerably more similar (Fig. 4). For example, in all months the Weibull $A$ (scale) parameters are higher in the $4 \mathrm{~km}: 57$ simulations, and the Weibull $A$ values are statistically similar in the $4 \mathrm{~km}: 41$ and $2 \mathrm{~km}: 41$ simulations (i.e., the $90 \%$ confidence intervals on $A$ overlap). These distributional differences are also evident in the mean wind speeds from the $4 \mathrm{~km}: 57$ output, which exceed values from the $4 \mathrm{~km}: 41$ by $0.2-0.6 \mathrm{~m} \mathrm{~s}^{-1}$ $\left(\right.$ mean $\left.=0.39 \mathrm{~m} \mathrm{~s}^{-1}\right)$, and in the estimates of the 90thpercentile value, which differ by a mean of $0.68 \mathrm{~m} \mathrm{~s}^{-1}$ and are consistently higher in the simulation with enhanced vertical resolution. These differences in wind speed distributions have relevance for wake development since they dictate the part of the thrust curve in which WT are operating. In general, for the WTs deployed in Iowa and specifically the Pomeroy cluster the higher prevalence of wind speeds above $10 \mathrm{~m} \mathrm{~s}^{-1}$ in the $4 \mathrm{~km}: 57$ output will tend to result in lower thrust coefficients and weaker wind turbine wakes.

\section{b. Systemwide gross $C F$ as a function of parameterization and resolution}

Consistent with the higher WT HH wind speeds reported above for the $4 \mathrm{~km}: 57$ simulations, power production and gross CF from the WT fleet deployed in Iowa are higher for both wind farm parameterizations in the $4 \mathrm{~km}: 57$ simulation (Fig. 5a). The median gross CF is $38 \%$ in simulations with Fitch for both the $4 \mathrm{~km}: 41$ and $2 \mathrm{~km}: 41$ simulations, but is $41 \%$ for the $4 \mathrm{~km}: 57$ simulation. Comparable values for EWP are $41 \%$ and $45 \%$, respectively. The entire probability distribution of $10-$ min gross $\mathrm{CF}$ are right shifted in power production output from both Fitch and EWP for the $4 \mathrm{~km}: 57$ simulation (Fig. 5a). Thus, virtually all percentile values of gross CF are higher in the enhanced vertical resolution simulations.

When simulated gross CF for the three resolutions and two wind farm parameterizations is compared by calendar month the following tendencies are observed (Fig. 5b):

1) EWP results in higher gross $C F$ than Fitch for all three resolutions in all calendar months. This difference has a mean value of approximately $3 \%-4 \%$ for the resolutions considered herein.

2) The difference in $\mathrm{CF}$ for a given wind farm parameterization as a function of resolution is comparable to the differences between the two wind farm parameterizations at a given resolution.

3) Simulations at all resolutions exhibit similar seasonality, but the impact of resolution on gross CF exhibits clear variation with calendar month. For example, output from May indicates only a small impact from changing the horizontal and vertical resolution used in WRF on simulated wind climates near WT HH (see 


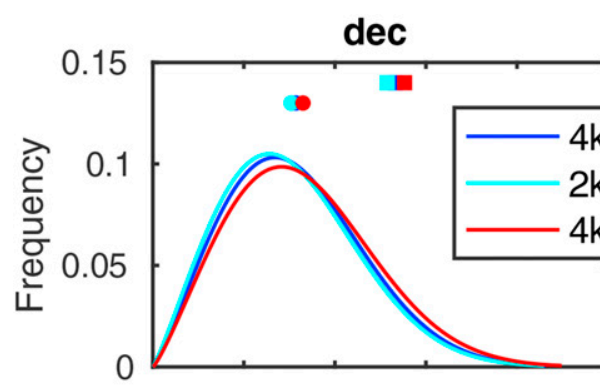

march
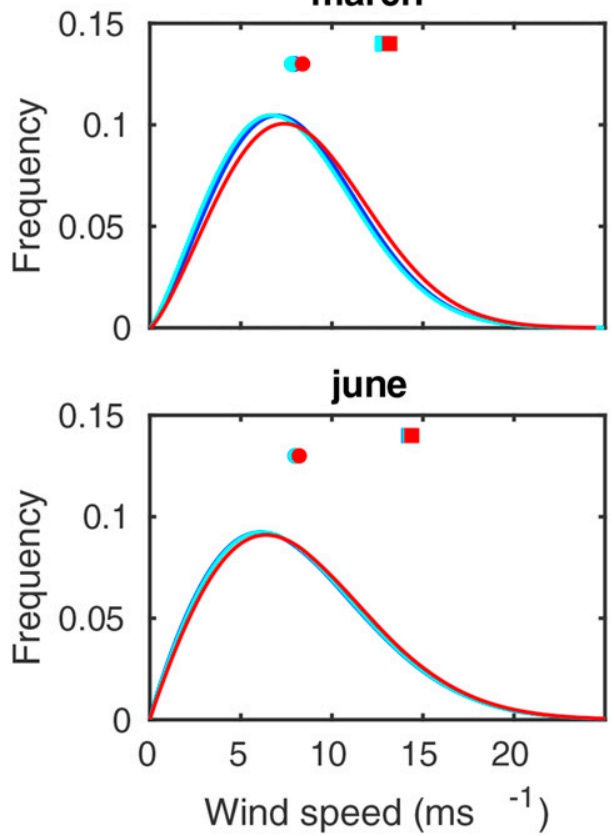

jan

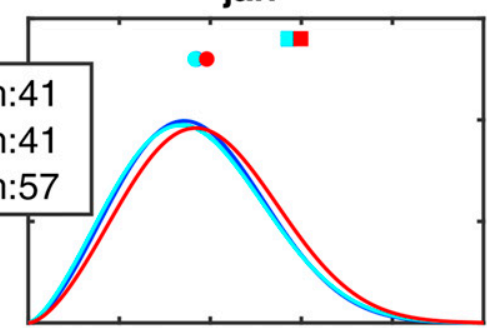

april

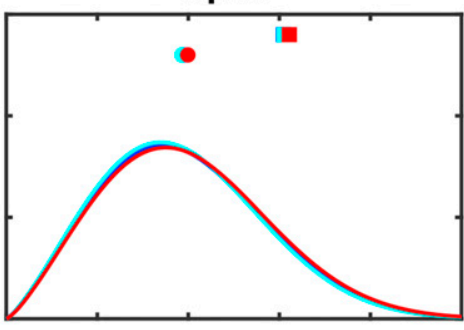

july

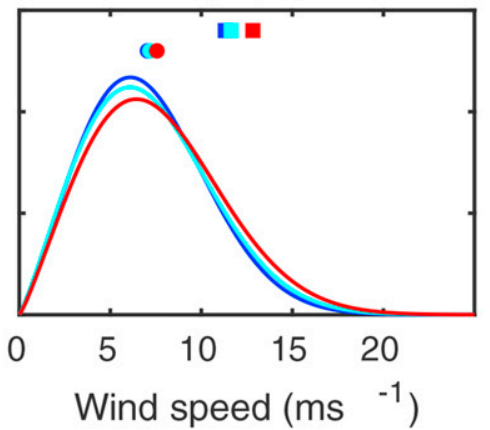

feb

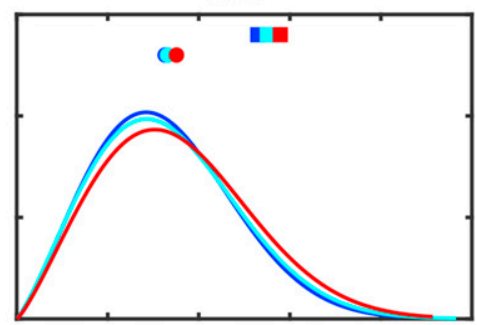

may

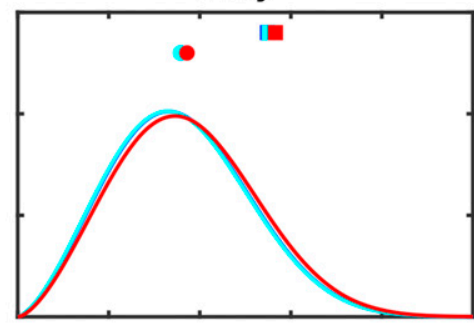

aug

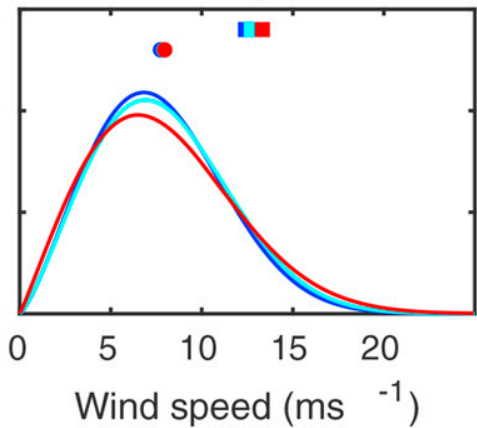

FIG. 4. Monthly Weibull distributions fitted to 10-min wind speeds at approximately the WT HH in the Pomeroy area (see Figs. 1 and 2 for the location) from WRF at the three different resolutions. Also shown are the 90th- (squares) and 50th- (circles) percentile wind speeds computed from the raw 10-min time series of wind speeds. To aid legibility, the mean wind speed and 90th-percentile wind speed in each month are shown at an arbitrary frequency of 0.13 and 0.14 , respectively. The three simulation resolutions are 4-km horizontal grid spacing with 41 vertical layers $(4 \mathrm{~km}: 41)$, 2-km horizontal grid spacing with 41 vertical layers $(2 \mathrm{~km}: 41)$, and 4-km horizontal grid spacing with 57 vertical layers (i.e., 2 times the density of vertical levels in approximately the lowest $2 \mathrm{~km})(4 \mathrm{~km}: 57)$.

examples for the Pomeroy subdomain in Fig. 6) and a relatively small impact from grid spacing on gross CF. In this month, consistent with previous research (Fitch et al. 2012), for the resolutions tested, there is only a weak dependence of wake behavior, electrical power production and gross $\mathrm{CF}$ to the number of vertical layers and/or horizontal resolution. However, in other calendar months the impact from resolution on wind climate simulated without WT and on power production from both wind farm parameterizations is considerably larger (e.g., March).

4) The resolution impacts on power production and gross CF do not appear to be solely the product of changes in the wind climate. For example, as shown in Fig. 4, in output from April the Weibull distributions, mean and 90th-percentile wind speed at approximate mean WT $\mathrm{HH}$ are virtually indistinguishable in output from d02_noWT at the three resolutions. However, gross $\mathrm{CF}$ exhibits substantial differences with model resolution during this month.

5) There is a general tendency for the simulations at $4 \mathrm{~km}$ with 57 vertical levels to be associated with the highest gross $\mathrm{CF}$ in both wind farm parameterizations. In eight of the nine months, simulations with both Fitch and EWP wind farm parameterizations exhibit highest gross CF for the $4 \mathrm{~km}: 57$ resolution. However, this is not uniformly the case. For the climate of August 2008, the simulation at 2-km horizontal grid spacing and 41 vertical layers is associated with highest gross $\mathrm{CF}$ in both EWP and Fitch. 

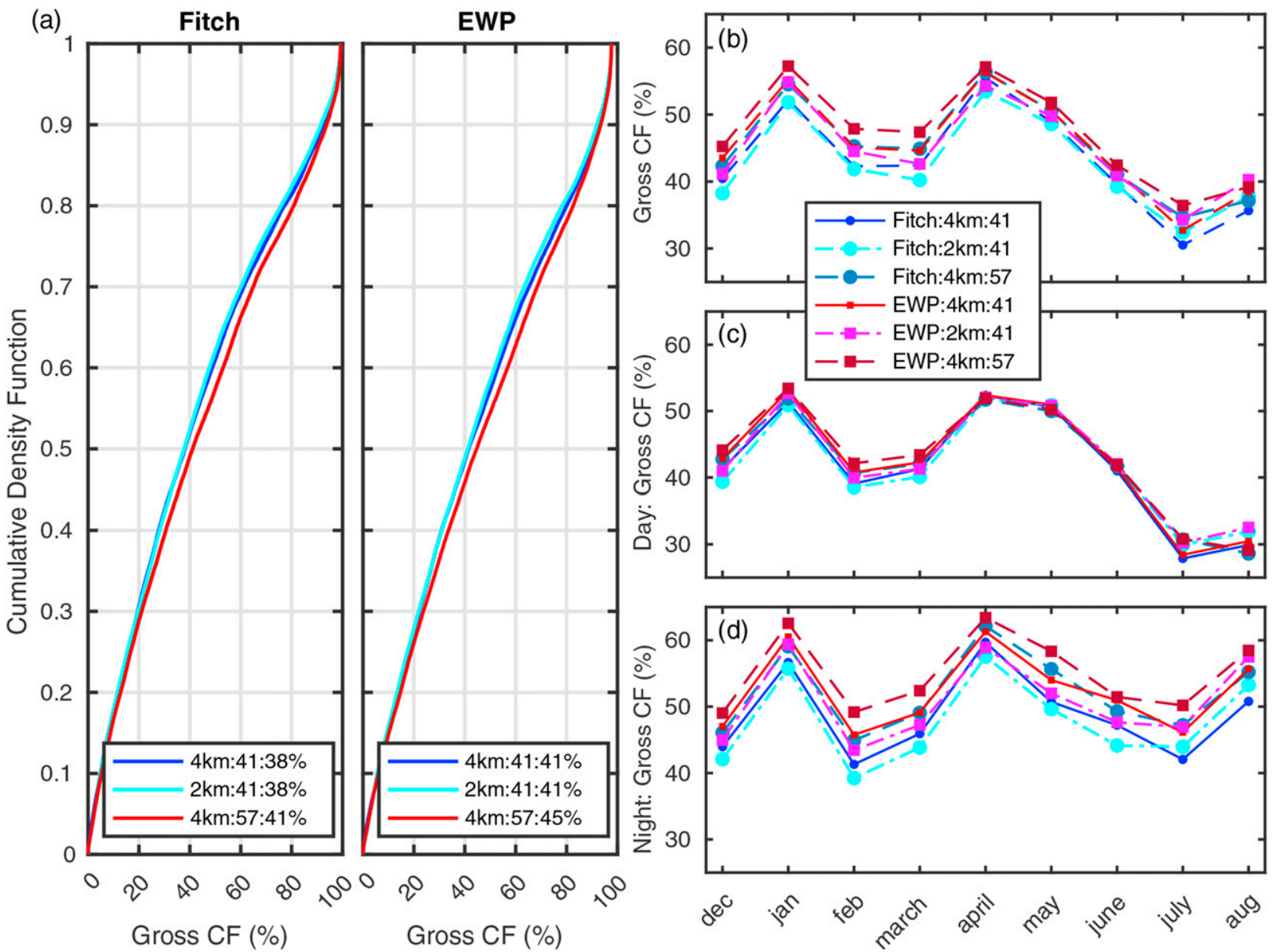

FIG. 5. (a) Cumulative density function of systemwide gross CF for all WT in Iowa (as of end of 2014) as computed for all 10-min periods (1 Dec 2007-31 Aug 2008) for the three resolutions and two wind farm parameterizations (Fitch and EWP). The legend also shows the median overall systemwide gross CF. (b) Monthly gross CF for all WT in Iowa computed for the two wind farm parameterizations (Fitch and EWP) and the three resolutions. (c) As in (b), but for daytime conditions (from midday until 1600, local time). (d) As in (b), but for nighttime (from midnight to 0400 , local time) conditions. The three simulation resolutions are 4-km horizontal grid spacing with 41 vertical layers (4 km:41), 2-km horizontal grid spacing with 41 vertical layers (2 km:41), and 4-km horizontal grid spacing with 57 vertical levels (i.e., 2 times the density of vertical layers in approximately the lowest $2 \mathrm{~km})(4 \mathrm{~km}: 57)$.

The seasonality in modeled response to wind farm parameterization and resolution potentially derive from seasonality in atmospheric stability and thus variations in ambient turbulence levels and wind climates. As described above, these variations in ambient turbulence intensity have also been invoked as a possible source of the differences in analysis of the two wind farm parameterizations on- and offshore. To investigate the postulate described above that the two wind farm parameterizations will differ most in stable (low TKE) conditions, power output from the simulations were also conditionally sampled by hour of the day and calendar month. Nighttime conditions are most likely to be associated with stable stratification in the lower boundary layer and are described here using output from 0700 to 1059 UTC (0000 to 0400 local time). Conversely, daytime conditions are most likely to be dominated by unstable conditions and are described here using output from 1900 to 2259 UTC (1200 to 1600 local time). The results of this conditional sampling indicate clear support for the postulate that the wind farm parameterizations exhibit greatest discrepancies under stable stratification (i.e., during nighttime conditions; cf. Figs. 5c and 5d). This analysis further indicates that the influence of resolution on wake behavior and propagation and consequences for gross $\mathrm{CF}$ is also more clearly manifest at night (Fig. 5d).

\section{c. Wake profiles and downstream recovery as a function of parameterization and resolution}

Horizontal planes of the median fractional velocity deficit $v d_{(x, y, z)}$ at approximately WT HH in all grid cells 

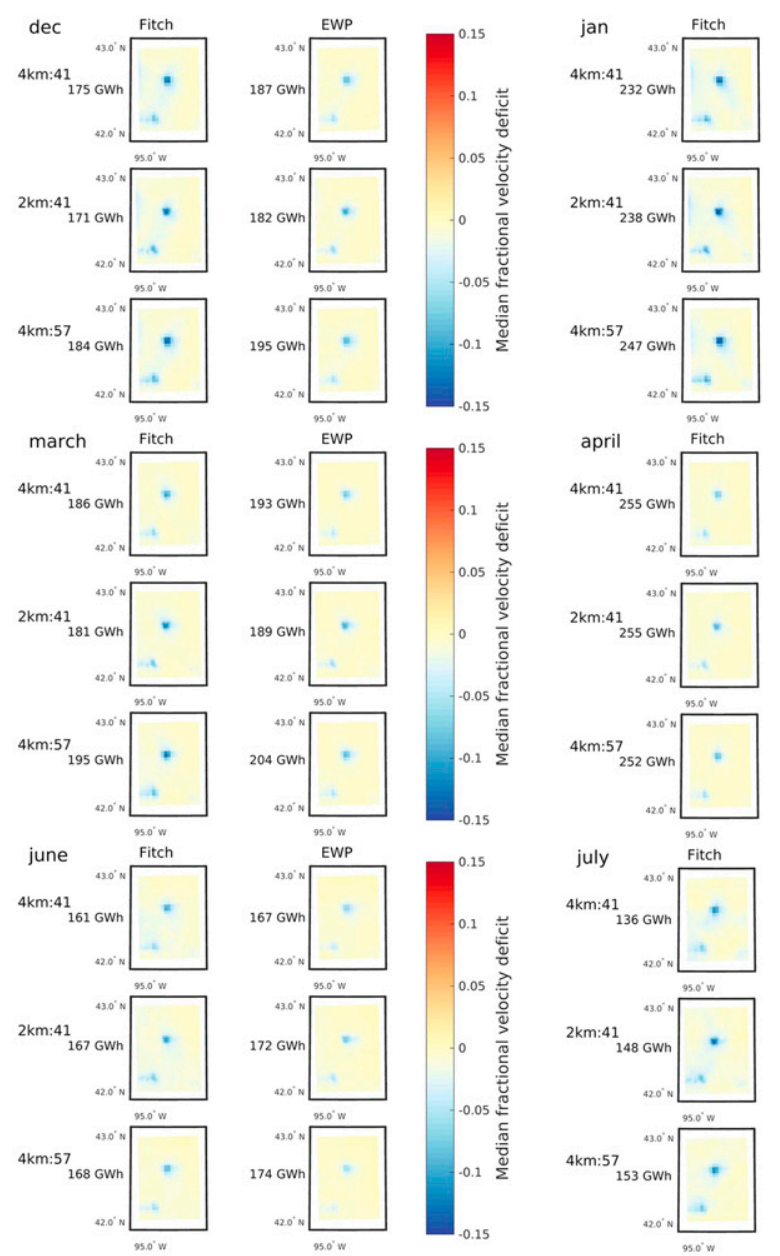

FIG. 6. Horizontal slices of median fractional velocity deficit at approximately WT HH through a subset of d02 covering the Pomeroy wind farm cluster and adjacent areas (see Figs. 1 and 2 for the location of this subdomain). This subdomain covers an area of approximately $80 \mathrm{~km} \times$ $100 \mathrm{~km}$. Each section of six plots shows a separate calendar month for each wind farm parameterization (columns) and the three resolutions (rows). The values stated near each plot indicate the gross power production during that month as derived from WT in the subdomain.

within the Pomeroy subdomain also exhibit clear evidence that wakes within WT arrays are of smaller magnitude when EWP is applied in all calendar months (Fig. 6). The gross power production from WT in this subdomain exhibit a similar pattern to the systemwide gross CF values given in Fig. 5 and generally are higher in simulations with EWP than Fitch. They also tend to increase with higher vertical resolution. Further, the downstream distance needed for the fractional velocity deficit to recover to $5 \%$ and $2 \%$ of the freestream value (from d02_noWT) is also shorter in simulations with EWP (Fig. 7). During the winter months (December-February, inclusive) over $15 \%$ of grid cells within the Pomeroy area exhibit median fractional velocity deficits of over $2 \%$ in simulations at $4 \mathrm{~km}: 41$ while less than $8 \%$ do in the equivalent output from EWP. This is true for all resolutions (Fig. 7). Indeed, for the resolutions used herein, there is only one calendar month in which a greater fraction
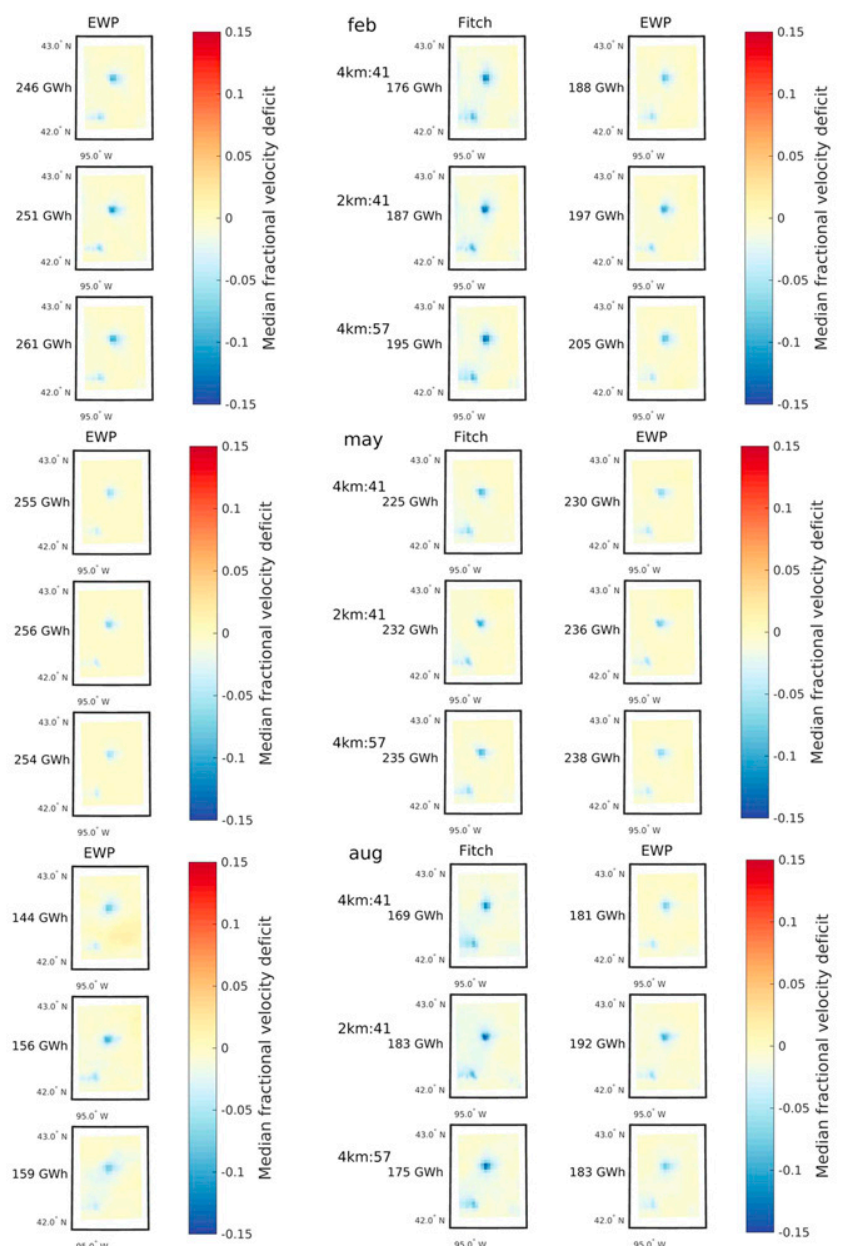


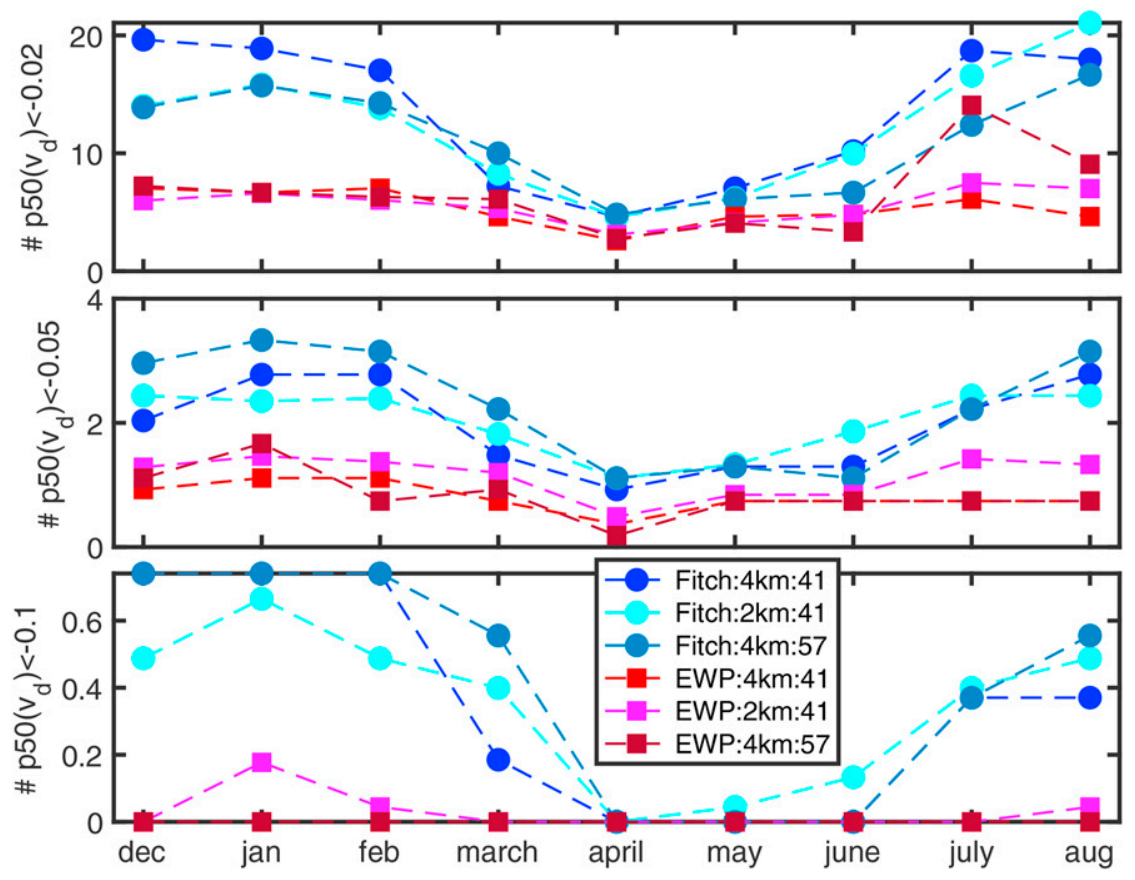

FIG. 7. Fraction (shown in percent) of grid cells within the subdomain centered over Pomeroy wherein the median fractional velocity deficit at approximately WT HH is less than (top) $2 \%$, (middle) $5 \%$, and (bottom) $10 \%$, as shown by month for the three different resolutions and two wind farm parameterizations. The three simulation resolutions are 4-km horizontal grid spacing with 41 vertical layers ( $4 \mathrm{~km}: 41)$, $2-\mathrm{km}$ horizontal grid spacing with 41 vertical layers ( $2 \mathrm{~km}: 41)$, and 4-km horizontal grid spacing with 57 vertical levels (i.e., 2 times the density of vertical levels in about the lowest $2 \mathrm{~km})(4 \mathrm{~km}: 57)$.

$0.9 \mathrm{~m}^{2} \mathrm{~s}^{-2}$ ) than in d02_EWP where it derives solely from the enhancement of wind shear (Fig. 9). The amount of shear-induced TKE production in EWP is largest in the summer months, when it reaches maximum mean gridcell values at approximately $2 \mathrm{HH}$ of up to $0.11 \mathrm{~m}^{2} \mathrm{~s}^{-2}$ but is generally $<0.1 \mathrm{~m}^{2} \mathrm{~s}^{-2}$. For example, in March 2008, the maximum enhancement of grid cell added TKE close to WT HH in the Pomeroy cluster from d02_Fitch is 0.49_ $0.71 \mathrm{~m}^{2} \mathrm{~s}^{-2}$, while in d02_EWP it is $<0.06 \mathrm{~m}^{2} \mathrm{~s}^{-2}$ for all three resolutions (Fig. 9). Consistent with the difference in the wind farm parameterization the region of maximum enhancement of TKE is observed within wind farms in Fitch but horizontally displaced from grid cells containing WT in EWP. The vertical profile of added TKE in simulations with Fitch and EWP exhibits some sensitivity to both horizontal and vertical resolution in all months. The maximum gridcell mean added TKE values (i.e., d02_Fitch minus d02_noWT) over the Pomeroy wind farm cluster at hub height is higher in the simulations with both higher horizontal grid spacing for all calendar months, and is higher in the simulations with a greater number of vertical levels except in August. For example, in March (Fig. 9) the maximum gridcell mean added TKE is $0.49 \mathrm{~m}^{2} \mathrm{~s}^{-2}$ in the $4 \mathrm{~km}: 41$ simulation,
$0.64 \mathrm{~m}^{2} \mathrm{~s}^{-2}$ in the $2 \mathrm{~km}: 41$, and $0.56 \mathrm{~m}^{2} \mathrm{~s}^{-2}$ in the $4 \mathrm{~km}: 57$. At approximately 2 times the WT HH, the maximum gridcell mean added TKE is $0.47 \mathrm{~m}^{2} \mathrm{~s}^{-2}$ in the $4 \mathrm{~km}: 41$ simulation, $0.71 \mathrm{~m}^{2} \mathrm{~s}^{-2}$ in the $2 \mathrm{~km}: 41$, and $0.37 \mathrm{~m}^{2} \mathrm{~s}^{-2}$ in the $4 \mathrm{~km}: 57$. An overview of the differences in TKE produced by the two wind farm parameterizations is given in Fig. 10 for the Pomeroy area for heights of $\sim \mathrm{HH}$ and $\sim 2 \times \mathrm{HH}$. In this figure the spatial patterns of median added TKE for each calendar month at the two heights are examined to identify the grid cell with largest $\triangle \mathrm{TKE}$ $\left(\mathrm{TKE}_{\mathrm{d} 02 \_\mathrm{xxxx}}\right.$ minus $\left.\mathrm{TKE}_{\mathrm{d} 02 \_n o w T}\right)$. As shown, the relative magnitude of TKE added due to enhanced wind shear (EWP) is considerably smaller than the amount added to represent the direct aerodynamic production of TKE from WTs (Fitch). The difference also exhibits a strong seasonal cycle. Further, the model resolution has a profound impact on both the amount of added TKE and the vertical distribution of additional TKE.

\section{Technical aspects of the simulations of wind farm wakes using WRF}

In perturbation experiments, simulations are conducted to assess the impact of a specific phenomenon on the 

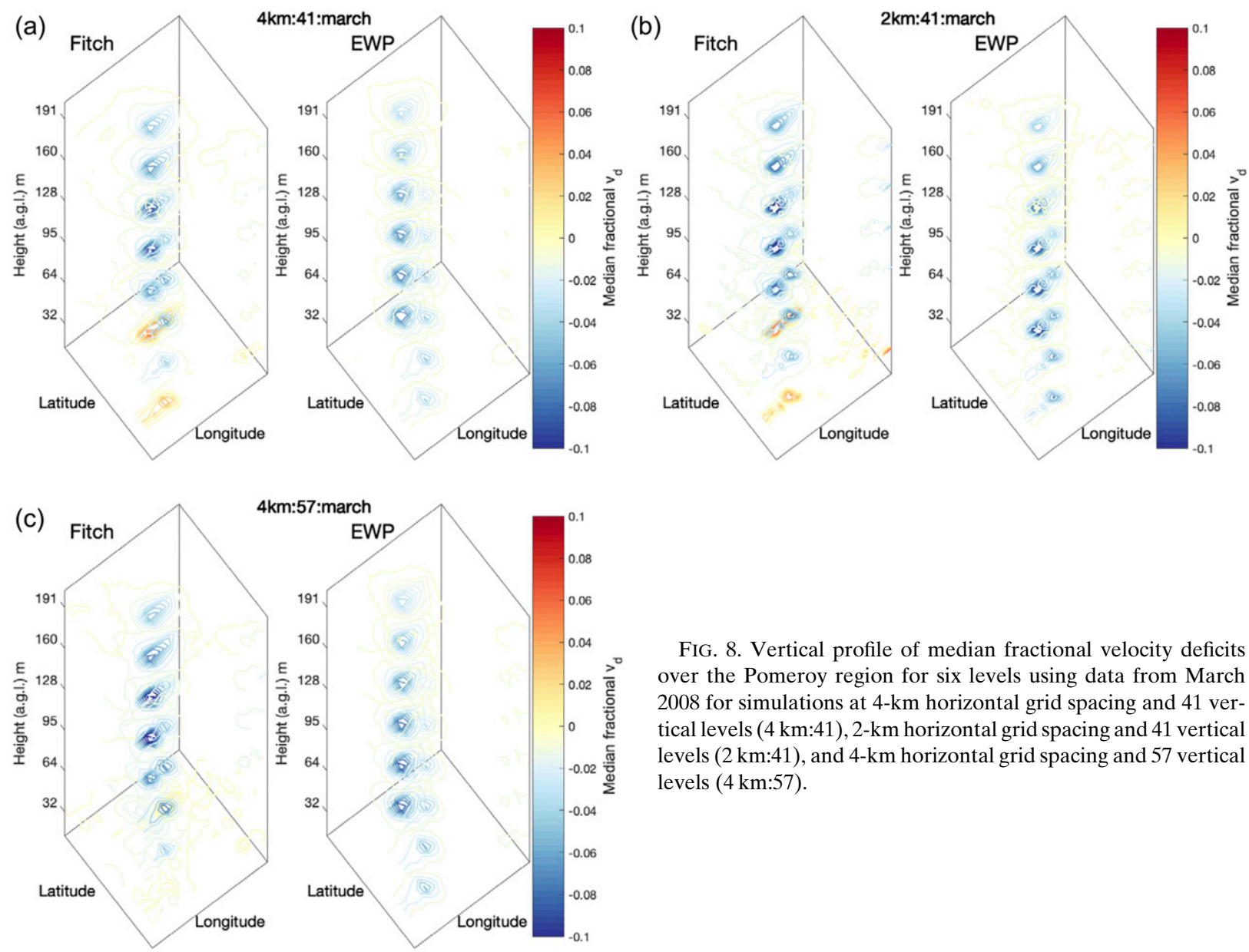

resultant atmospheric conditions. These experiments most commonly involve undertaking two completely independent simulations and generating difference fields from output with the phenomena present (e.g., the action of wind turbines described) minus a control under the presumption that those differences derive solely from the physical source(s) under investigation and that are described numerically. However, this implicit assumption is rarely made explicit and there is increasing evidence that a difference between model simulations "produces a rapid propagation of very small changes throughout all prognostic model variables at a rate many times the speed of sound" as a result of the model's higher-order spatial discretization schemes, allowing the communication of numerical error across many grid points with each time step." (Ancell et al. 2018; Langhans et al. 2012). Recent research suggests " $[\mathrm{t}] \mathrm{his}$ phenomenon is found to be unavoidable within the Weather Research and Forecasting (WRF) Model even when using techniques such as digital filtering or numerical diffusion," and further, that while these errors were reduced by implementation of double precision they were not eliminated despite the

substantial computing cost of double-precision simulations (Ancell et al. 2018).

As described in section 2, the simulations presented herein were conducted with a single outer domain and three "simultaneously" computed inner domains (d02_Fitch, d02_EWP, and d02_noWT). The output from three inner domains are used herein to compute timewise perturbations that derive from the operation of wind turbines as manifest in the two different wind farm parameterizations. However, our approach does not eradicate the presence of numerical noise in the output we generated. For example, output from virtually all grid cells exhibit some 10-min periods with a normalized fractional difference in wind speed close to WT HH (e.g., d02_Fitch minus d02_noWT normalized by d02_noWT) that are not consistent with physical reasoning. These outliers are almost entirely confined to the warm-season months and do not occur in December, January, February, or March. For example, for the $4 \mathrm{~km}: 41$ simulation of August $\sim 0.1 \%$ of grid cells and time stamps in the Pomeroy area exhibit fractional velocity deficit values in excess of 5 . These outliers are uniformly associated with time periods 
march
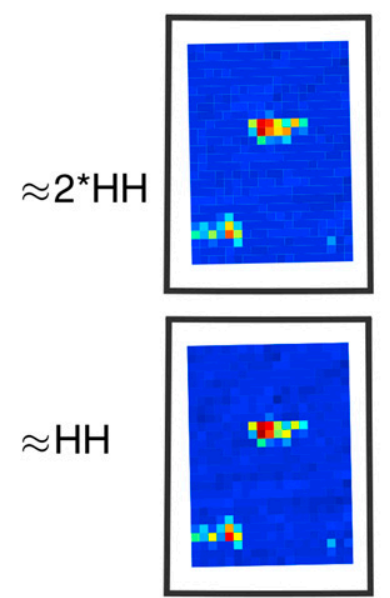

$4 \mathrm{~km}: 41$
Fitch
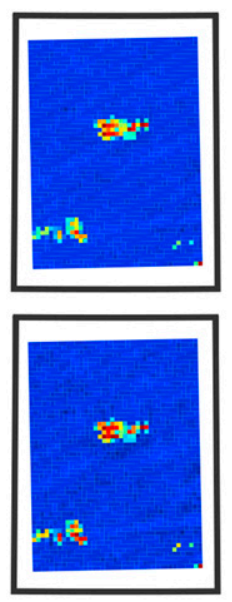

$2 \mathrm{~km}: 41$
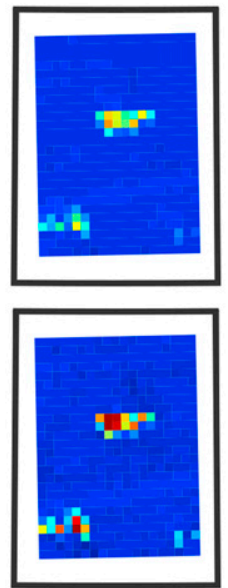

$4 \mathrm{~km}: 57$
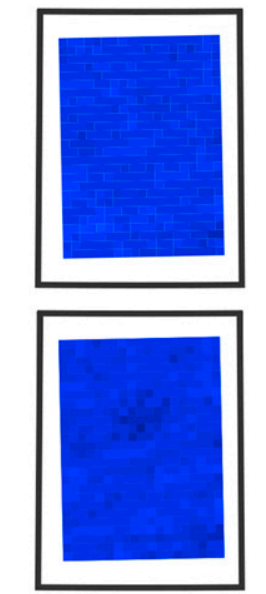

$4 \mathrm{~km}: 41$
EWP
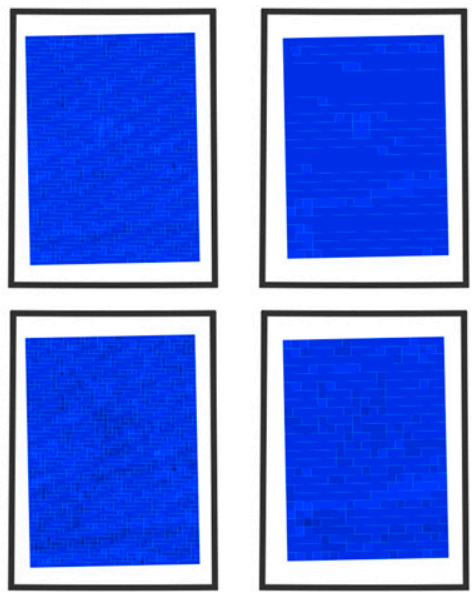

$2 \mathrm{~km}: 41$

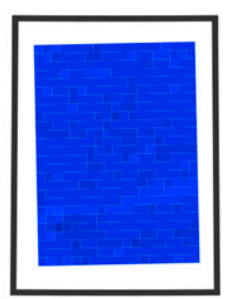

$4 \mathrm{~km}: 57$

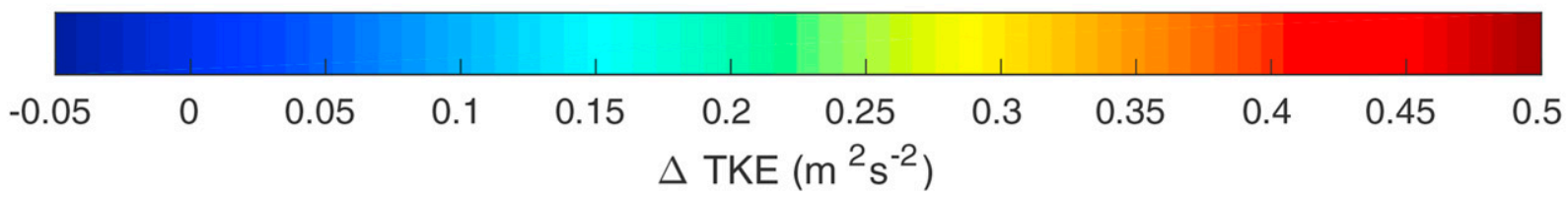

FIG. 9. Horizontal cross sections of median $\triangle$ TKE (d02_Fitch or d02_EWP minus d02_noWT) over the Pomeroy area computed using output from March 2008 and shown for two heights: one close to WT HH and the other at approximately 2 times the WT HH as based on output from Fitch and EWP applied at the three resolutions: 4-km horizontal grid spacing with 41 vertical layers (4 km:41), 2-km horizontal grid spacing with 41 vertical layers $(2 \mathrm{~km}: 41)$, and $4-\mathrm{km}$ horizontal grid spacing with 57 vertical levels (i.e., 2 times the density of vertical layers in approximately the lowest $2 \mathrm{~km})(4 \mathrm{~km}: 57)$.

with very low wind speeds in the d02_noWT output. Use herein of median as a metric of the central tendency to describe fractional velocity deficits and added TKE make the results resilient to these outliers, but it is worthy of note that such features are present in the simulations at all resolutions.

Given that most previous perturbation experiments have not employed three simultaneously computed inner domains, to further examine issues of numerical stability, additional experiments were undertaken in which the order in which the three inner domains are computed was varied but otherwise all parameters were fixed. These simulations were performed for 15-31 July, inclusive, at the $4 \mathrm{~km}: 41$ resolution. The order of the inner domains is as follows:

For simulation 1, noWT was d02, Fitch was d03, and EWP was d04.

For simulation 2, noWT was d02, EWP was d03, and Fitch was d04.

For simulation 3, Fitch was d02, EWP was d03, and noWT was d04.

This experiment is designed to quantify the magnitude of differences in output for d02_XXXX that may arise from variations of the order in which the inner domains were computed. Analysis of the output indicate there are indeed marked variations in both the wind components in the third model layer from the noWT inner domains and the 10-min power output from the wind farm parameterizations according to domain order (Fig. 11). When output from a given domain (e.g., $U$ component of the wind in the third model layer from noWT) are compared, the results are numerically identical if that domain was computed in the same rank order in the two simulations (e.g., noWT was the first inner domain in simulations 1 and 2), but otherwise they differ. For example, the mean ratios of electrical power production summed over all WTs in Iowa in each 10-min period for Fitch (simulation1/simulation2, simulation1/simulation3, and simulation2/simulation3) are 0.987, 0.995, and 0.998. Comparable results for power output from EWP are $0.977,0.977$, and 1.000. Thus, it appears that the order in which the inner domains are computed has an influence on the output. The three sets of simulations performed at different resolutions and presented herein used a constant order for the inner domains and thus comparisons across these simulations remain valid. However, this as yet unreported, phenomenon has important implications for 


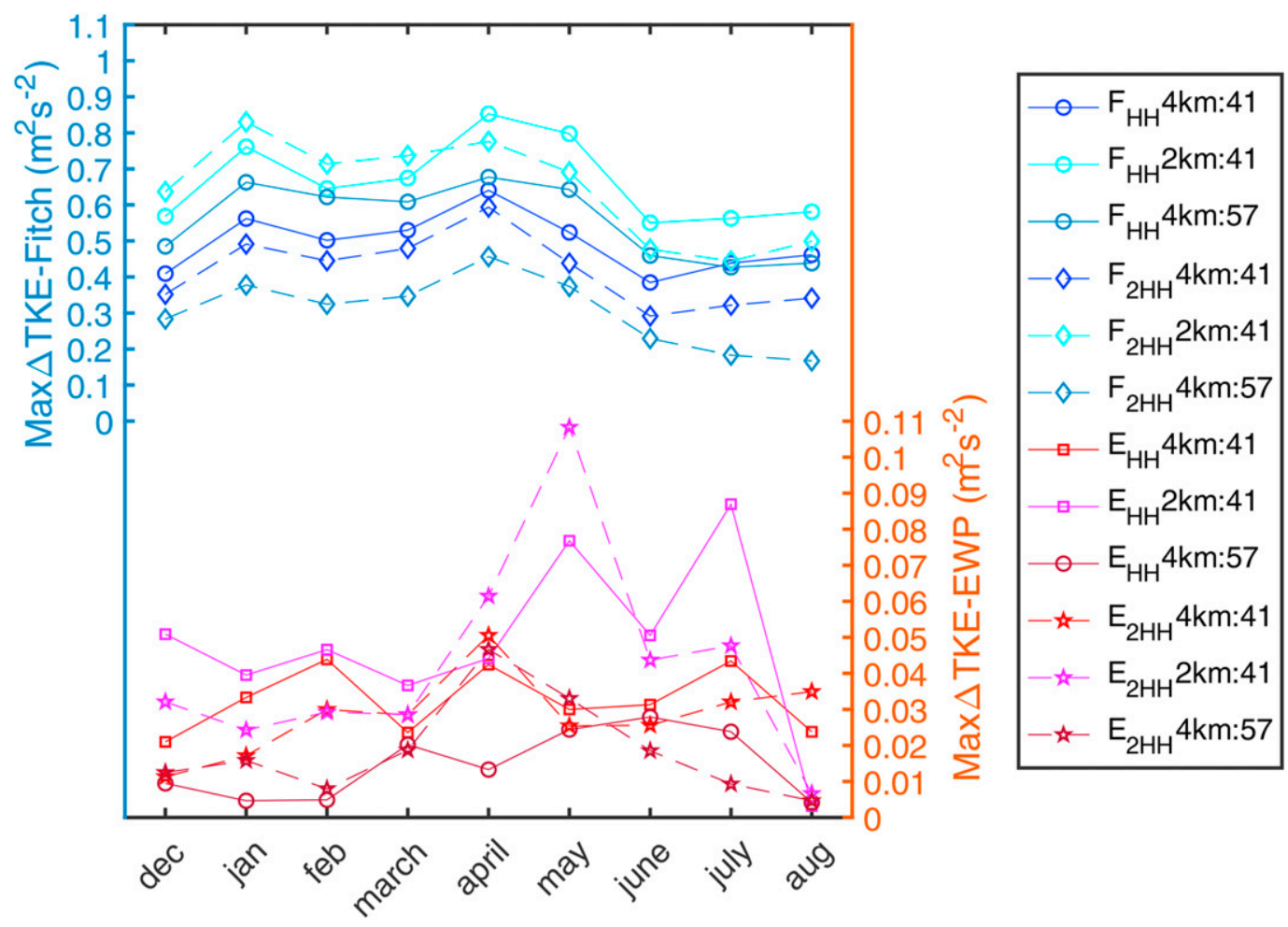

FIG. 10. Maximum median $\triangle T K E$ (d02_Fitch or d02_EWP minus d02_noWT) in any grid cell within the Pomeroy area for heights close to WT HH and at 2 times WT HH as based on output from Fitch and EWP applied at the three resolutions: 4-km horizontal grid spacing with 41 vertical layers $(4 \mathrm{~km}: 41), 2-\mathrm{km}$ horizontal grid spacing with 41 vertical layers $(2 \mathrm{~km}: 41)$, and 4-km horizontal grid spacing with 57 vertical levels (i.e., 2 times the density of vertical levels in about the lowest $2 \mathrm{~km})(4 \mathrm{~km}: 57)$.

perturbation experiments conducted within the wind energy community. Future work will examine whether the presence/absence/magnitude of the domain order dependence and the occurrence of numerical outliers exhibits a dependence on system architecture and/or compiler and/or specific compiler settings.

\section{Concluding remarks}

Sensitivity analyses were conducted to examine the influence of vertical and horizontal grid spacing in the WRF Model on the wind climate and flow perturbations (wakes) and gross $\mathrm{CF}$ derived using two wind farm parameterizations (Fitch and EWP). The three sets of simulations are performed for a domain covering the Midwestern United States and focused on Iowa. They include one conducted at 4-km horizontal grid spacing and 41 vertical layers $(4 \mathrm{~km}$ : $41)$, one with halved horizontal grid spacing $(2 \mathrm{~km} \times 2 \mathrm{~km}$, and 41 vertical layers; $2 \mathrm{~km}: 41$ ), and one with doubled vertical resolution in the lowest portion of the atmosphere (i.e., a total of 57 layers in the vertical direction) and a horizontal grid spacing of $4 \mathrm{~km}(4 \mathrm{~km}: 57)$ (Figs. 1 and 3).
Irrespective of the resolution used, gross simulated CF for wind turbines in Iowa is higher in simulations that employ the EWP wind farm parameterization than when Fitch is applied (Fig. 5). Mean monthly power output is $4.6 \%-5.6 \%$ higher when EWP is applied than when Fitch is applied, depending on the precise resolution used. Monthly gross $\mathrm{CF}$ from Fitch ranges from a low of $30.5 \%$ in July for the $4 \mathrm{~km}: 41$ resolution to $56.3 \%$ in April for the $4 \mathrm{~km}: 57$, while for EWP the lowest gross CF (also attained in July) is $32.7 \%$ (for $4 \mathrm{~km}: 41$ ) and the highest is in January and is $57.2 \%$ ( $4 \mathrm{~km}: 57)$; the value in April is $57.1 \%$ (4 km:57) (Fig. 5). There is a general tendency for the simulations at $4 \mathrm{~km}$ with 57 vertical levels to be associated with the highest gross CF in both wind farm parameterizations. This sensitivity to resolution (and wind farm parameterization) is particularly marked during stable stratification and thus is strongly manifest in nighttime hours (Fig. 5). It is at least partly due to the shift in the wind climate at WT HH toward higher values in the simulations with higher vertical resolution (Fig. 4). Illustrative results from a subregion of Iowa that encompasses the Pomeroy wind farm cluster indicate that velocity deficits in excess of $2 \%$ and 

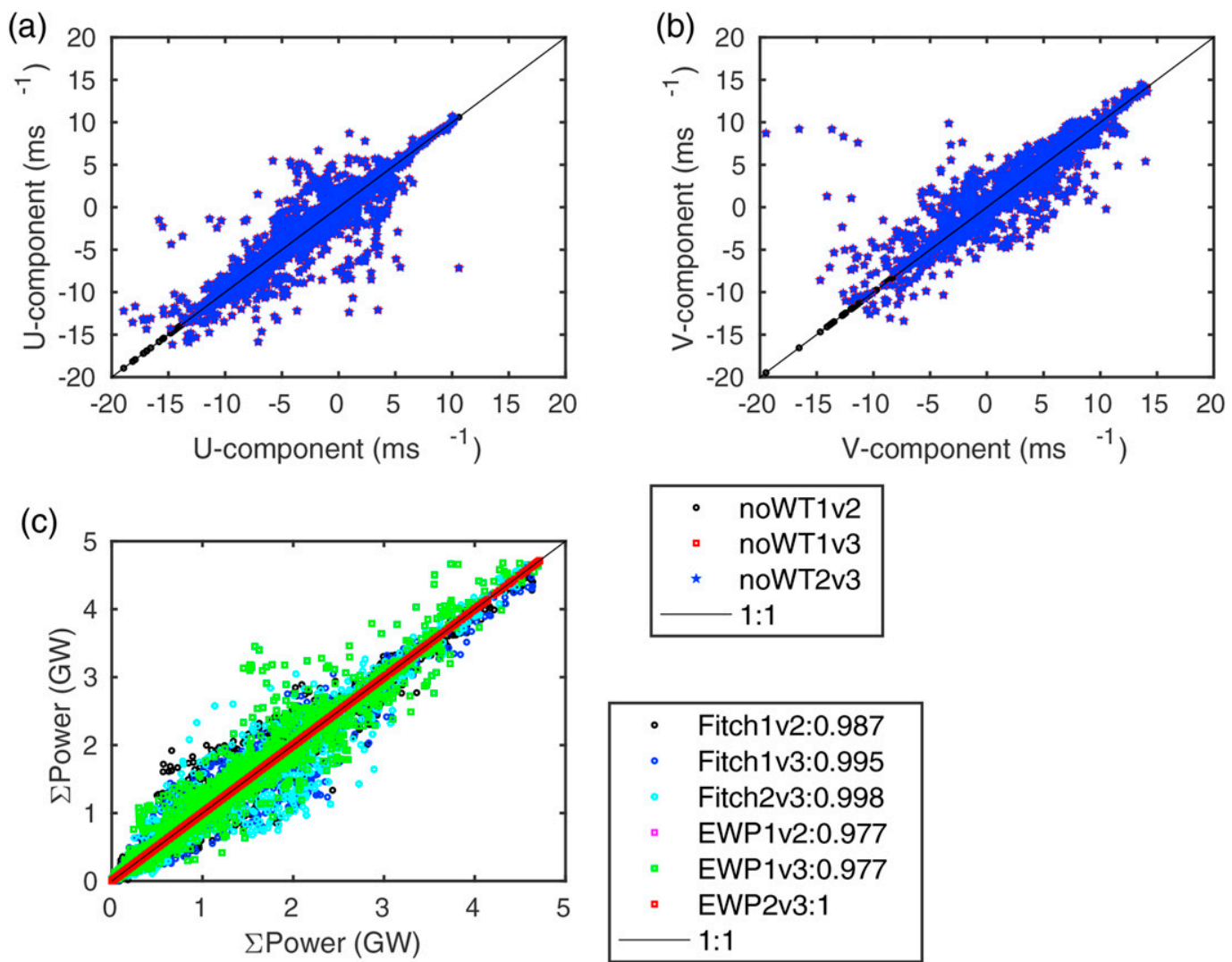

FIG. 11. Scatterplots of 10-min values of (a) $U$ and (b) $V$ components of the wind speed in an example grid cell $(100,100)$ from the noWT inner domains and (c) sum of power production in EWP and Fitch from all grid cells during 15-31 Jul 2008 for the three additional simulations performed at 4-km horizontal grid spacing with 41 vertical layers $(4 \mathrm{~km}: 41)$. The simulation number indicates runs conducted with the following orders of inner domain: for simulation 1, no_WT was d02, Fitch was d03, and EWP was d04; for simulation 2, no_WT was d02, EWP was d03, and Fitch was d04; and for simulation 3, Fitch was d02, EWP was d03, and no_WT was d04.

$5 \%$ of the freestream condition (i.e., output from a noWT domain) cover considerably larger areas when the Fitch wind farm parameterization is employed and the enhancement of TKE in more intense and expressed over a larger spatial area. The area defined as within the "wind shadow" (i.e., with velocity deficits of $>2 \%$ ) is generally largest in the $4 \mathrm{~km}: 41$ simulations with Fitch and exhibits lowest variability with resolution in the spring months (March-May, inclusive) (Fig. 7). The lower wake intensity in the EWP formulation means it consistently generates higher power production than Fitch. This sensitivity of power production to wind farm parameterization is generally of greater magnitude than that resulting from the halving of horizontal grid spacing for the simulations presented herein and is comparable to doubling the number of vertical levels.

The simulations presented herein were conducted using three simultaneously computed inner domains. This methodological decision was made in attempt to reduce the sensitivity of the analyses to chaos seeding in independent simulations. However, as shown, there is a sensitivity of the model output to the order in which the inner domains are computed. To provide a context for those differences, Table 3 presents the ratios of mean power output for conditions during 15-31 July 2008 with the WT fleet of 2014 from the different sources: wind farm parameterization, resolution, and domain order. The results imply that the differences in mean power output between the two wind farm parameterizations and between simulations with a given wind farm parameterization but at different resolutions are of larger magnitude than the impact from inner domain simulation order. Further, consistent with results from the long-term simulations, the sensitivity of power output to increasing the number of vertical layers in the lowest portion of the atmosphere is greater than the sensitivity to increasing the horizontal resolution.

It is important to acknowledge the following: 1) Halving the horizontal grid spacing from 4 to $2 \mathrm{~km}$ leads to an increase by a factor of 4 in computing demands, 
TABLE 3. Comparison of model sensitivity in mean gross power production during 15-31 Jul 2008 from variations in model resolution, wind farm parameterization, and order in which the inner domains are computed. For each simulation pair, the value given is the ratio of the mean power produced; thus, for the comparison of EWP and Fitch output for the $4 \mathrm{~km}: 41$, the value of 1.091 indicates the mean power production from EWP is 1.091 times that from Fitch.

\begin{tabular}{|c|c|c|c|}
\hline Wind farm parameterization & & Varied item & \\
\hline $\begin{array}{l}\text { Fitch } \\
\text { EWP }\end{array}$ & $\begin{array}{c}4 \mathrm{~km}: 41 / 2 \mathrm{~km}: 41 \\
0.894 \\
0.918\end{array}$ & $\begin{array}{c}\text { Model resolution } \\
4 \mathrm{~km}: 41 / 4 \mathrm{~km}: 57 \\
0.869 \\
0.893\end{array}$ & $\begin{array}{c}2 \mathrm{~km}: 41 / 4 \mathrm{~km}: 57 \\
0.972 \\
0.972\end{array}$ \\
\hline EWP/Fitch & $\begin{array}{c}4 \mathrm{~km}: 41 \\
1.091\end{array}$ & $\begin{array}{l}\text { Model resolution } \\
2 \mathrm{~km}: 41 \\
1.062\end{array}$ & $\begin{array}{c}4 \mathrm{~km}: 57 \\
1.062\end{array}$ \\
\hline Fitch & $\begin{array}{l}\text { 2nd vs } 3 \text { rd } \\
0.987\end{array}$ & $\begin{array}{l}\text { Order of domains } \\
\text { 2nd vs 1st } \\
0.997 \\
\text { Order of domains } \\
\text { 3rd vs 2nd } \\
0.982\end{array}$ & $\begin{array}{l}\text { 3rd vs 1st } \\
1.010\end{array}$ \\
\hline
\end{tabular}

whereas doubling the number of vertical layers in the lower atmosphere leads to less than a doubling of computing demand. Thus, any future study will necessarily have to balance the advantages of conducting longer simulations to sample a wide array of atmospheric conditions, or increasing the domain to sample a wider array of regional climates against enhancing the horizontal and/or vertical levels. 2) Research such as that presented herein focuses on only a limited part of the total uncertainty space in the simulation of wind climates and wind farm wake effects, and that additional uncertainty in such simulations derives from variations in, for example, PBL parameterizations and the land-cover products used to provide boundary conditions. Nevertheless, our analysis is predicated on comparatively sophisticated treatment of the mechanisms by which WT interact with the atmosphere, is of long duration and is conducted at high spatial resolution $(4 \mathrm{~km} \times 4 \mathrm{~km}$ or $2 \mathrm{~km} \times 2 \mathrm{~km}$ grid cells). Thus, inferences drawn regarding the sensitivity of simulated wind climates, wakes and electrical power generation sensitivity to model resolution and wind farm parameterization are comparatively robust. In the absence of long-term experimental data and/or availability of detailed power production data from suites of operating wind farms, it is not currently possible to determine which of the two parameterizations exhibit greater fidelity and/ or which model resolution is optimal to use in analyses of array-array interactions. However, the sensitivities of power production and wake behavior are of sufficient magnitude to indicate the need for such observational studies. Further, the importance of the wind farm parameterization to determining wake intensity and propagation and the seasonality of the wake response to resolution (and wind farm parameterization) should be used to provide important context for previous research that has typically been conducted over short time periods, at a single resolution, and/or using a single wind farm parameterization. Pending availability of suitable computing resources and release of long-term power production data from individual wind farms, future work should include multiyear simulations and detailed validation against those observations.

Acknowledgments. This work was supported by the U.S. Department of Energy (DoE) (DE-SC0016438) and computing resources from the National Science Foundation (ACI-1541215 and TG-ATM170024) and DoE (DEAC02-05CH11231). Two reviewers and the editor are gratefully acknowledged. The USGS Wind Turbine Database is available online (https://eerscmap.usgs.gov/ uswtdb/). ERA-Interim output is available online (http:// apps.ecmwf.int/datasets/). The NOAA-NCEP Real Time Global sea surface temperature analyses are available online (http://www.nco.ncep.noaa.gov/pmb/products/sst/). The Fitch wind farm parameterization is included in all WRF releases. The EWP model code is available online (https://doi.org/10.5281/zenodo.33435). NetCDF files containing the derived variables from our WRF output that underpin each of the analyses and figures presented herein are available from the Zenodo repository along with the WRF name lists (https://doi.org/10.5281/zenodo.3556724). The entire $70 \mathrm{~TB}$ of WRF output is available upon request from the authors via the DoE HPPS system.

\section{REFERENCES}

Ancell, B. C., A. Bogusz, M. J. Lauridsen, and C. J. Nauert, 2018: Seeding chaos: The dire consequences of numerical noise in NWP perturbation experiments. Bull. Amer. Meteor. Soc., 99, 615-628, https://doi.org/10.1175/BAMS-D-17-0129.1. 
AWEA, 2019: U.S. wind industry annual market report: Year ending 2018. American Wind Energy Association Rep., 172 pp.

Beljaars, A., 1995: The parametrization of surface fluxes in largescale models under free convection. Quart. J. Roy. Meteor. Soc., 121, 255-270, https://doi.org/10.1002/qj.49712152203.

Berg, J., N. Troldborg, N. N. Sørensen, E. Patton, and P. P. Sullivan, 2017: Large-eddy simulation of turbine wake in complex terrain. J. Phys.: Conf. Ser., 854, 012003, https:// doi.org/10.1088/1742-6596/854/1/012003.

Carvalho, D., A. Rocha, M. Gomez-Gerteira, and C. Santos, 2012: A sensitivity study of the WRF model in wind simulation for an area of high wind energy. Environ. Modell. Software, 33, 23-34, https://doi.org/10.1016/j.envsoft.2012.01.019.

Cervarich, M. C., S. Baidya Roy, and L. Zhou, 2013: Spatiotemporal structure of wind farm-atmospheric boundary layer interactions. Energy Procedia, 40, 530-536, https://doi.org/10.1016/ j.egypro.2013.08.061.

Christiansen, M. B., and C. B. Hasager, 2005: Wake effects of large offshore wind farms identified from satellite SAR. Remote Sens. Environ., 98, 251-268, https://doi.org/10.1016/j.rse.2005.07.009.

Churchfield, M. J., S. Lee, J. Michalakes, and P. J. Moriarty, 2012: A numerical study of the effects of atmospheric and wake turbulence on wind turbine dynamics. J. Turbul., 13, https:// doi.org/10.1080/14685248.2012.668191.

Dee, D. P., and Coauthors, 2011: The ERA-Interim reanalysis: Configuration and performance of the data assimilation system. Quart. J. Roy. Meteor. Soc., 137, 553-597, https://doi.org/ 10.1002/qj.828.

Dörenkämper, M., B. Witha, G. Steinfeld, D. Heinemann, and M. Kühn, 2015: The impact of stable atmospheric boundary layers on wind-turbine wakes within offshore wind farms. J. Wind Eng. Ind. Aerodyn., 144, 146-153, https://doi.org/ 10.1016/j.jweia.2014.12.011.

Draxl, C., A. N. Hahmann, A. Peña, and G. Giebel, 2014 Evaluating winds and vertical wind shear from Weather Research and Forecasting model forecasts using seven planetary boundary layer schemes. Wind Energy, 17, 39-55, https://doi.org/10.1002/we.1555.

Dudhia, J., 1989: Numerical study of convection observed during the winter monsoon experiment using a mesoscale two-dimensional model. J. Atmos. Sci., 46, 3077-3107, https://doi.org/10.1175/ 1520-0469(1989)046<3077:NSOCOD>2.0.CO;2.

Ferrier, B. S., Y. Jin, Y. Lin, T. Black, E. Rogers, and G. DiMego, 2002: Implementation of a new grid-scale cloud and precipitation scheme in the NCEP Eta model. 15th Conf. on Numerical Weather Prediction, San Antonio, TX, Amer. Meteor. Soc., 280-283.

Fitch, A. C., 2015: Climate impacts of large-scale wind farms as parameterized in a global climate model. J. Climate, 28, 6160 6180, https://doi.org/10.1175/JCLI-D-14-00245.1.

- 2016: Notes on using the mesoscale wind farm parameterization of Fitch et al. (2012) in WRF. Wind Energy, 19, 17571758, https://doi.org/10.1002/we.1945.

—_, J. B. Olson, J. K. Lundquist, J. Dudhia, A. K. Gupta, J. Michalakes, and I. Barstad, 2012: Local and mesoscale impacts of wind farms as parameterized in a mesoscale NWP model. Mon. Wea. Rev., 140, 3017-3038, https://doi.org/ 10.1175/MWR-D-11-00352.1.

,-- , and -2013 : Parameterization of wind farms in climate models. J. Climate, 26, 6439-6458, https://doi.org/10.1175/ JCLI-D-12-00376.1.

Frandsen, S., and R. Barthelmie, 2002: Local wind climate within and downwind of large offshore wind turbine clusters. Wind Eng., 26, 51-58, https://doi.org/10.1260/030952402320775290.
Froese, M., 2019: FERC data suggests renewable capacity could be quadruple that of fossil fuels by 2021. Windpower Engineering and Development, https://www.windpowerengineering.com/ ferc-data-suggests-renewable-capacity-could-be-quadruplethat-of-fossil-fuels-by-2021/.

Giorgi, F., and W. J. Gutowski Jr., 2015: Regional dynamical downscaling and the CORDEX initiative. Annu. Rev. Environ. Resour., 40, 467-490, https://doi.org/10.1146/annurev-environ-102014-021217.

Hahmann, A. N., C. L. Vincent, A. Peña, J. Lange, and C. B. Hasager, 2015: Wind climate estimation using WRF model output: method and model sensitivities over the sea. Int. J. Climatol., 35, 3422-3439, https://doi.org/10.1002/joc.4217.

Kain, J. S., 2004: The Kain-Fritsch convective parameterization: An update. J. Appl. Meteor., 43, 170-181, https://doi.org/10.1175/ 1520-0450(2004)043<0170:TKCPAU > 2.0.CO;2.

Keith, D., J. DeCarolis, D. Denkenberger, D. Lenschow, S. Malyshev, S. Pacala, and P. Rasch, 2004: The influence of large-scale wind power on global climate. Proc. Natl. Acad. Sci. USA, 101, 1611516120, https://doi.org/10.1073/pnas.0406930101.

Langhans, W., J. Schmidli, and C. Schär, 2012: Mesoscale impacts of explicit numerical diffusion in a convection-permitting model. Mon. Wea. Rev., 140, 226-244, https://doi.org/10.1175/ 2011MWR3650.1.

Larsén, X. G., S. Ott, J. Badger, A. N. Hahmann, and J. Mann, 2012: Recipes for correcting the impact of effective mesoscale resolution on the estimation of extreme winds. J. Appl. Meteor. Climatol., 51, 521-533, https://doi.org/10.1175/JAMC-D-11-090.1.

Lee, J. C., and J. K. Lundquist, 2017: Evaluation of the wind farm parameterization in the Weather Research and Forecasting Model (version 3.8. 1) with meteorological and turbine power data. Geosci. Model Dev., 10, 4229-4244, https://doi.org/ 10.5194/gmd-10-4229-2017.

Lundquist, J., K. DuVivier, D. Kaffine, and J. Tomaszewski, 2019: Costs and consequences of wind turbine wake effects arising from uncoordinated wind energy development. Nat. Energy, 4, 26-34, https://doi.org/10.1038/s41560-018-0281-2.

Miller, L. M., and D. W. Keith, 2018: Climatic impacts of wind power. Joule, 2, 2618-2632, https://doi.org/10.1016/j.joule.2018.09.009.

—, N. A. Brunsell, D. B. Mechem, F. Gans, A. J. Monaghan, R. Vautard, D. W. Keith, and A. Kleidon, 2015: Two methods for estimating limits to large-scale wind power generation. Proc. Natl. Acad. Sci. USA, 112, 11169-11174, https://doi.org/ 10.1073/pnas.1408251112.

Mlawer, E. J., S. J. Taubman, P. D. Brown, M. J. Iacono, and S. A. Clough, 1997: Radiative transfer for inhomogeneous atmospheres: RRTM, a validated correlated- $k$ model for the longwave. J. Geophys. Res., 102, 16663-16 682, https://doi.org/ 10.1029/97JD00237.

Nakanishi, M., and H. Niino, 2006: An improved Mellor-Yamada level-3 model: Its numerical stability and application to a regional prediction of advection fog. Bound.-Layer Meteor., 119, 397-407, https://doi.org/10.1007/s10546-005-9030-8.

NREL, 2008: 20\% Wind energy by 2030: Increasing wind energy's contribution to US electricity supply. National Renewable Energy Laboratory Rep. DOE/GO-102008-2567, 248 pp., https://www.nrel.gov/docs/fy08osti/41869.pdf.

- 2015: Wind vision: A new era for wind power in the United States. National Renewable Energy Laboratory Rep. DOE/ GO-102015-4557, 348 pp., https://www.nrel.gov/docs/fy15osti/ 63197-2.pdf.

Nunalee, C. G., and S. Basu, 2014: Mesoscale modeling of coastal lowlevel jets: Implications for offshore wind resource estimation. Wind Energy, 17, 1199-1216, https://doi.org/10.1002/we.1628. 
Porté-Agel, F., M. Bastankhah, and S. Shamsoddin, 2020: Windturbine and wind-farm flows: A review. Bound.-Layer Meteor., https://doi.org/10.1007/s10546-019-00473-0, in press.

Pryor, S. C., M. Nielsen, R. J. Barthelmie, and J. Mann, 2004: Can satellite sampling of offshore wind speeds realistically represent wind speed distributions? Part II: Quantifying uncertainties associated with sampling strategy and distribution fitting methods. J. Appl. Meteor., 43, 739-750, https://doi.org/ 10.1175/2096.1.

— , R. J. Barthelmie, and T. Shepherd, 2018a: The influence of real-world wind turbine deployments on regional climate. J. Geophys. Res. Atmos., 123, 5804-5826, https://doi.org/ 10.1029/2017JD028114.

, — - A. N. Hahmann, T. J. Shepherd, and P. J. H. Volker, 2018b: Downstream effects from contemporary wind turbine deployments. J. Phys.: Conf. Ser., 1037, 072010, https://doi.org/ 10.1088/1742-6596/1037/7/072010.

_ Volker, 2019: Wind farm wakes simulated using WRF. J. Phys.: Conf. Ser., 1256, 012025, https://doi.org/10.1088/17426596/1256/1/012025.

Rife, D. L., J. O. Pinto, A. J. Monaghan, C. A. Davis, and J. R. Hannan, 2010: Global distribution and characteristics of diurnally varying low-level jets. J. Climate, 23, 5041-5064, https://doi.org/10.1175/2010JCLI3514.1.

Sanderse, B., S. Van der Pijl, and B. Koren, 2011: Review of computational fluid dynamics for wind turbine wake aerodynamics. Wind Energy, 14, 799-819, https://doi.org/10.1002/ we.458.

Shepherd, T. J., R. J. Barthelmie, and S. C. Pryor, 2020: Sensitivity of wind turbine array downstream effects to the parameterization used in WRF. J. Appl. Meteor. Climatol., https://doi.org/ 10.1175/JAMC-D-19-0135.1, in press.

Siedersleben, S. K., and Coauthors, 2018: Evaluation of a wind farm parametrization for mesoscale atmospheric flow models with aircraft measurements. Meteor. Z., 27, 401-415, https:// doi.org/10.1127/metz/2018/0900.

_ kinetic energy (WRF 3.8.1) over large offshore wind farms. Geosci. Model Dev., https://doi.org/10.5194/gmd-2019-100, in press.

Sīle, T., A. Hahmann, B. Witha, M. Dörenkämper, M. Baltscheffsky, and S. Söderberg, 2018: Applying numerical weather prediction models to the production of New European Wind Atlas: Sensitivity studies of the wind climate to the planetary boundary layer parametrization. 59th Int. Scientific Conf. on Power and Electrical Engineering of Riga Technical University (RTUCON), Riga, Latvia, IEEE, https://doi.org/ 10.1109/RTUCON.2018.8659881.
Stevens, R. J., and C. Meneveau, 2017: Flow structure and turbulence in wind farms. Annu. Rev. Fluid Mech., 49, 311-339, https://doi.org/10.1146/annurev-fluid-010816-060206.

Tewari, M., and Coauthors, 2004: Implementation and verification of the unified NOAH land surface model in the WRF Model. 20th Conf. on Weather Analysis and Forecasting/16th Conf. on Numerical Weather Prediction, 14.2a, Seattle, WA, Amer. Meteor. Soc., https://ams.confex.com/ams/pdfpapers/69061.pdf.

Troldborg, N., 2008: Actuator line modeling of wind turbine wakes. Ph.D. dissertation, Technical University of Denmark, 134 pp.

— J. J. Norensen, and R. Mikkelsen, 2010: Numerical simulations of wake characteristics of a wind turbine in uniform inflow. Wind Energy, 13, 86-99, https://doi.org/10.1002/we.345.

van der Horst, D., and S. Vermeylen, 2010: Wind theft, spatial planning and international relations. Renewable Energy Law Policy Rev., 1, 67-75, https://www.jstor.org/stable/24324588.

Vanderwende, B. J., B. Kosović, J. K. Lundquist, and J. D. Mirocha, 2016: Simulating effects of a wind-turbine array using LES and RANS. J. Adv. Model. Earth Syst., 8, 1376-1390, https://doi.org/10.1002/2016MS000652.

Vautard, R., and Coauthors, 2014: Regional climate model simulations indicate limited climatic impacts by operational and planned European wind farms. Nat. Commun., 5, 3196, https:/ doi.org/10.1038/ncomms4196.

Volker, P. J. H., J. Badger, A. N. Hahmann, and S. Ott, 2015: The Explicit Wake Parametrisation V1.0: A wind farm parametrisation in the mesoscale model WRF. Geosci. Model Dev., 8, 3481-3522, https://doi.org/10.5194/GMD-8-3715-2015.

— A. N. Hahmann, J. Badger, and H. E. Jørgensen, 2017: Prospects for generating electricity by large onshore and offshore wind farms. Environ. Res. Lett., 12, 034022, https:// doi.org/10.1088/1748-9326/aa5d86.

Wang, Q., K. Luo, R. Yuan, S. Zhang, and J. Fan, 2019: Wake and performance interference between adjacent wind farms: Case study of Xinjiang in China by means of mesoscale simulations. Energy, 166, 1168-1180, https://doi.org/10.1016/ j.energy.2018.10.111.

Wilks, D. S., 2011: Statistical Methods in the Atmospheric Sciences. 3rd ed. Elsevier, 676 pp.

Xia, G., M. C. Cervarich, S. Baidya Roy, L. Zhou, J. R. Minder, P. A. Jimenez, and J. M. Freedman, 2017: Simulating impacts of real-world wind farms on land surface temperature using the WRF Model: Validation with observations. Mon. Wea. Rev., 145, 4813-4836, https://doi.org/10.1175/ MWR-D-16-0401.1.

Zhao, J., Z.-H. Guo, Z.-Y. Su, Z.-Y. Zhao, X. Xiao, and F. Liu, 2016: An improved multi-step forecasting model based on WRF ensembles and creative fuzzy systems for wind speed. Appl. Energy, 162, 808-826, https://doi.org/10.1016/j.apenergy.2015.10.145. 